\title{
STATISTICAL ASSESSMENT OF IN-PLANE MASONRY PANELS USING LIMIT ANALYSIS WITH SLIDING MECHANISM
}

\author{
Alejandro Jiménez Rios ${ }^{1}$, Marco Pingaro ${ }^{2}$, Emanuele Reccia ${ }^{3}$, Patrizia Trovalusci ${ }^{4}$
}

\begin{abstract}
Historical masonry structures have a great interest in civil engineering since they constitute a large part of the world's building heritage. In this paper the effects that different geometrical (panel ratio, block ratio, bond type) and mechanical (friction ratio) parameters have on the in-plane structural response of brick masonry panels are investigated. A discrete modelling approach, based on a Limit Analysis, capable of reproducing sliding mechanisms, formulation by one of the Authors have been adopted, enhanced and implemented. Results, in terms of collapse multipliers and collapse mechanisms, are presented and analysed following a systematic statistical approach. Statistically significant effects have been found for each factor considered. Furthermore, the statistical model adopted included non-linear terms that allowed to identify whether the effect of one parameter on the response depended on the level of any other parameters. Thus, it was observed that two-way factor interactions played an important role on the in-plane response of masonry panels. The panel ratio-friction ratio two-way factor interaction was the one with a more significant effect.
\end{abstract}

Keywords: Limit Analysis, Friction, Masonry, Panels, No-tension contacts, Statistical assessment.

\section{INTRODUCTION}

Masonry is a non-homogeneous material constituted by blocks (stone, bricks or adobes) and joints (mortar or dry) (Lourenço 1998). The structural behaviour of masonry is affected by geometry, disposition and mechanical properties of its constituents, as well as by the aspect ratios of the panels and of the blocks, the arrangement of

\footnotetext{
${ }^{1}$ Dept. of Structural and Geotechnical Engineering., Sapienza University of Rome, Via Gramsci 53, 00197, Rome, Italy. ORCID: 0000-0003-4470-255X E-mail: alejandro.jimenezrios@ uniroma1.it

${ }^{2}$ Dept. of Structural and Geotechnical Engineering., Sapienza University of Rome, Via Gramsci 53, 00197, Rome, Italy. ORCID: 0000-0002-7037-8661 E-mail: marco.pingaro@ uniroma1.it

${ }^{3}$ Dept. of Civil and Environmental Engineering and Architecture, University of Cagliari, Via Marengo 2, 09123, Cagliari, Italy. ORCID: 0000-0003-0499-4295 E-mail: emanuele.reccia@unica.it

${ }^{4}$ Dept. of Structural and Geotechnical Engineering., Sapienza University of Rome, Via Gramsci 53, 00197, Rome, Italy. ORCID: 0000-0001-7946-3590 E-mail: patrizia.trovalusci@uniroma1.it
} 
blocks and scale factor of the units and the whole panel (Baggio and Trovalusci 1993; Trovalusci and Masiani 1999; Trovalusci and Masiani 2003; Pau and Trovalusci 2012; Baraldi et al. 2018).

Through history several masonry block arrangements, also known as bond types or textures, have been implemented perhaps aiming at enhancing the response of masonry structures. The work of (Huerta Fernández 2004), based on the experimental results obtained by Rondelet in a series of masonry specimens on the XIX century, highlighted the fact that masonry joints negatively affect masonry resistance.

It was observed by (Vasconcelos and Lourenç̧o 2009) that shape and arrangement of units in a masonry panel clearly affect ductility and energy dissipation capabilities of a series of stone masonry panels tested under hysteretic dynamic loading. The influence of bond type on the structural response of masonry panels has been further studied by (Drougkas et al. 2015) who have reported an extensive list of masonry mechanical properties based on their bond type. In (Taguchi and Cuadra 2015) a comparison between english and flemish masonry walls has been carried out demonstrating that a larger volume of joints in a flemish wall would lead to a weaker structure in comparison with an english bond masonry wall. Furthermore, (Shrestha et al. 2020) implemented a micro-modelling numerical approach to simulate the structural behaviour of masonry panels composed with different bond types and concluded that the elastic response of the panels was not influenced by the bond type, only the ultimate failure load was affected by this parameter.

In particular, the in-plane structural response of masonry panels is not only influenced by the panel aspect ratio but also by block shape factor as well on scale factor as pointed out by (Giuffrè 1990; Ponte et al. 2019). In (Anthoine et al. 1995) a strong negative relation between masonry lateral resistance and panel ratio has been reported. This observation has been further verified by several authors (Kikuchi et al. 2003; Drysdale Robert and Hamid Ahmed 2005; Haach et al. 2011). After analysing a series of masonry panels composed of blocks with different aspect ratios, (Baraldi et al. 2018) concluded that the in-plane collapse mechanism, and consequently the panel resistance, would be affected by the blocks geometry. Some other recent studies focus on the effects of the internal geometry of masonry walls (shape, size and textures of brick/blocks) (Pepe 2020; Pepe et al. 2020c).

Due to masonry heterogeneity and to the effect that geometrical parameters have on its behaviour, the simulation of masonry structural response and assessment is a complicated task. Over the past decades a variety of numerical approaches have been proposed by several authors trying to reproduce masonry structural behaviour at different scales and levels of detail. Among the more suitable strategies to capture masonry structural response are the so called block-based models (BBM). These are discrete models in which every masonry block is modelled along with a suitable formulation to represent the inter-block interactions. The main advantage of BBM is that masonry bond can be represented and accounted for. Furthermore, BBM are usually characterized by relatively simple mechanical constitutive models which require few input parameters (friction, cohesion, etc.) and provide clear results in terms of easily interpreted collapse mechanism and failure modes. A further description of BBM and al- 
ternative approaches available to reproduce masonry structural behaviour can be found in well-known review papers (Lourenço 2002; Roca et al. 2010; D'Altri et al. 2020).

Micromechanical models take into account the constituents, that is units and interfaces, made of mortar if present, between elements are separately modelled and to each part is assigned a properly calibrated constitutive law such as in (Lotfi and Shing 1994; Lourenço and Rots 1997; Oliveira and Lourenço 2004; Cecchi and Sab 2004; Alfano and Sacco 2006). In macromechanical models (Del Piero 1989; Gambarotta and Lagomarsino 1997; Roca et al. 2005), the heterogeneous medium is modelled as a continuum and the constitutive behaviour is usually described through phenomenologically based mathematical relations, also including damage or friction phenomena. Finally, the multiscale models represent a very promising approach for the analysis of masonry structures since they can accurately keep track of the the mechanical and geometrical properties of the material at the microstructure scale with a reduced computational cost if compared to a fully micromechanical model.

They are continuum models derived from finer descriptions and generally based on the classical homogenization strategies, (Addessi et al. 2018; Addessi et al. 2016; Greco et al. 2016; Greco et al. 2017) or on other coarse-graining strategies, based on the so-called Cauchy rule and its generalizations (Trovalusci 2014; Capecchi et al. 2011), also allowing the derivation of generalized continua such as micropolar continua able to properly account for scale effects, that in masonry materials are significant (Masiani and Trovalusci 1996; Trovalusci and Masiani 1999; Trovalusci and Masiani 2003; Trovalusci and Pau 2014; Leonetti et al. 2018; Reccia et al. 2018).

The more general approach is the Discrete Element Method (DEM) (Cundall and Strack 1979; Cundall and Hart 1992) originally developed for granular materials and then successfully applied to masonry (Lemos 2007) and its combination with Finite Elements (FEM/DEM)(Reccia et al. 2012; Smoljanović et al. 2013) in which blocks could be represented as a deformable or as a rigid bodies. Another very effective approach is the non-smooth contact dynamic method (NSCD) (Dubois et al. 2018; Clementi et al. 2020), in which blocks are modelled as rigid interacting bodies. In this framework, the so-called rigid block models (RBM) (Portioli et al. 2013; Angelillo et al. 2018; Baraldi et al. 2020; Casolo 2004; Casolo 2009) are particularly fit for historical masonries, where mortar is much more deformable than blocks and joints thickness is negligible.

Within the context of BBM, Limit Analysis permits the evaluation of the ultimate load capacity of the structure and its corresponding failure mechanism, requiring a limited number of material parameters, overcoming the common difficulties of obtaining reliable experimental data for historical masonry structures. Furthermore, Limit Analysis is largely recognized as a very effective tool to estimate collapse load and collapse mechanisms for masonry structures (Baggio and Trovalusci 1998; Baggio and Trovalusci 2000; Ferris and Tin-Loi 2001; Milani 2011; Portioli et al. 2014; Milani and Taliercio 2016; Rossi et al. 2020; Cascini et al. 2020; Grillanda et al. 2019) or masonry structures in presence of settlements (Landolfo et al. 2020; Pepe et al. 2020c; Tiberti et al. 2020).

The basic hypothesis, introduced by (Heyman 1966; Heyman 1969), upon which 
Limit Analysis would be applicable to masonry structures are: (a) sliding cannot occur, (b) masonry has no tensile strength, (c) masonry has an infinite compressive strength and (d) failure occurs under small displacements. Under hypothesis (a) masonry can be considered as a material with associative flow rules for which the normality rule holds. For these structures, however, hypothesis (a) is strongly limitative, as it reduces the collapse of a masonry structure only to the occurrence of hinging mechanisms, while in also sliding can be observed.

The first known pioneering contribute concerning the possibility to consider in the study of the collapse of masonry structures the presence of friction is due to Coulomb (Coulomb 1776). Coulomb recognises that in the presence of sliding mechanisms the solution is not unique and that the collapse load can be limited by minor and major bounds. The theorems of Limit Analysis currently formulated for materials with finite resistance to friction, which are described as non-standard materials with nonassociative flow rules, for which the normality rule is not satisfied, still confirm this finding. In particular, suitable lower and upper bounds for the collapse load of nonstandard materials, as systems with frictional interfaces, has been respectively identified with the collapse load of a standard material having an ideal yield surface with outward normal directed as the vector representing the plastic flow (plastic potential), and another standard material with the actual yield surface and ideal plastic flow directed as the normal to this surface, as a material with dilatant interfaces (Drucker 1953; Radenkovic 1961).

In this work, the strategy for tackling the problem proposed in (Baggio and Trovalusci 2000) was followed. This strategy is based on the solution of a linear programming problem (LP) obtained by replacing friction with dilatancy and it assumes an associative collapse mechanism for which the normality rule holds. Other strategies involve, in order to satisfy the normality rule, the modification of the yield surface such as in (Gilbert et al. 2006).

Starting from the work of (Baggio and Trovalusci 2000), a new version of the ALMA code (Analisi Limite Murature Attritive) has been developed based on the Limit Analysis (Pepe 2020; Pepe et al. 2020a; Pepe et al. 2020b; Pepe et al. 2021) namely ALMA 2.0. The new version of ALMA, by the adoption of the recent coding language Python $^{T M}$ and the advantages of the novel MOSEK library (www.mosek.com) optimization subroutine, overcomes the limitation in terms of the number of blocks with respect to the original version (Baggio and Trovalusci 2000) and it has been improved in order to take into account foundation settlement (Pepe et al. 2020c), cohesion between the joints and the effects of a retrofitting chain (Pepe 2020).

In this paper the effect of different geometrical and mechanical parameters in the in-plane structural response of brick masonry panels using a Limit Analysis approach capable of reproducing sliding mechanisms is presented. The main difference of this work with respect to parametric analysis performed by other authors (Bustamante 2003; Casapulla and Argiento 2018), is the fact that a systematic statistical approach has been implemented which has enabled the authors not only to identify, but also to quantify, the effect on the response of the different factors studied. This approach consisted in the application of a design of experiments (DOE) to a series of determin- 


\section{Subsection "Limit Analysis".} of the results are summarized.

\section{ADOPTED MODEL}

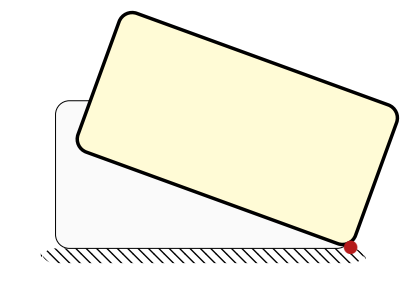

(a) Rotation

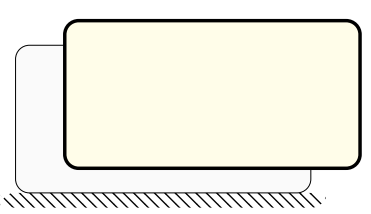

(b) Sliding

FIG. 1: Schematic representation of possible mechanisms for one-block structure

istic Limit Analysis simulations. With the data obtained from the DOE, a metamodel Montgomery 2019) was created and, subsequently, the effect that the studied parameers have in the response was analysed on the metamodel. First the formulation of the Limit Analysis implemented is described in section "Adopted model", followed by the description of the systematic parametric analysis used in section "Design of experiments (DOE)". Then, the results obtained in terms of collapse multipliers and collapse mechanisms are shown and discussed in section "Results and discussion". Finally, in section "Conclusions", the main conclusions drawn from the analysis and discussion

In this study the framework of the Limit Analysis has been adopted in accordance to the notation used in (Baggio and Trovalusci 1998; Baggio and Trovalusci 2000). The masonry structures have been described as a system of $n$ rigid blocks and $m$ joints unable to carry tension and resistant to sliding by friction, $f=\tan (\phi)$, where $\phi$ is the friction angle. Limited to the in-plane problems, the blocks can translate and rotate about the edges of the contact blocks (hinging) as well as slide along the joints as shown in Figure 1 in which a single block is depicted. It is important to notice that in case of sliding (Figure 1b) we assume dilatant behaviour, such that the block slides going up of the friction angle, $\phi$. This assumption is explained in the following

\section{Limit Analysis (kinematic approach)}

Let consider a system of $n$ parallelepiped blocks in two-dimensional space with the orthonormal basis $\boldsymbol{e}=\left\{e_{1}, e_{2}\right\}^{T}$. Over all single blocks the loads, applied in the respective centroid of mass of each $i^{\text {th }}$ rigid block, is

$$
\boldsymbol{f}^{i}=\boldsymbol{f}_{0}^{i}+\alpha \boldsymbol{f}_{L}^{i} \text {, with } i=1, \ldots, n,
$$

where $\boldsymbol{f}_{0}^{i}=\left\{f_{01}^{i}, f_{02}^{i}, m_{0}^{i}\right\}^{T}$ and $\boldsymbol{f}_{L}^{i}=\left\{f_{L 1}^{i}, f_{L 2}^{i}, m_{L}^{i}\right\}^{T}$ are the constant 'dead' and 'live' generalized loads vectors, respectively. As usual in the Limit Analysis the load vector in Equation 1 is split into two parts in which live loads are proportional to the dead loads through a non-negative coefficient $\alpha$, called load multiplier, as shown in Figure 2a. In both cases the vector $\boldsymbol{f}_{\star}^{i}$, with $\star=0, L$ contains the two components of 


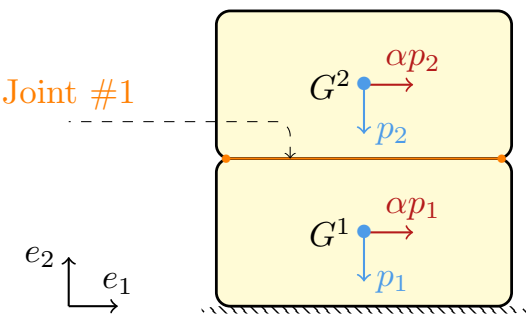

(a) dead and live loads global load vector $\boldsymbol{f}$. and $\epsilon$, respectively (Figure $2 \mathrm{~b}-2 \mathrm{c}$ ). static variables $\boldsymbol{\sigma}$.

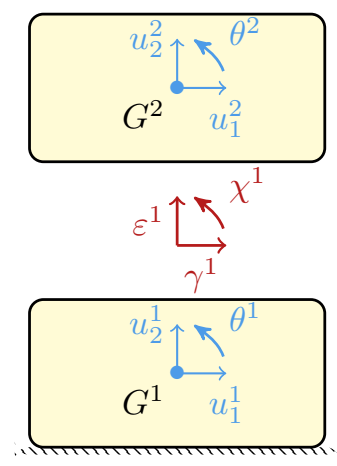

(b) kinematic variable

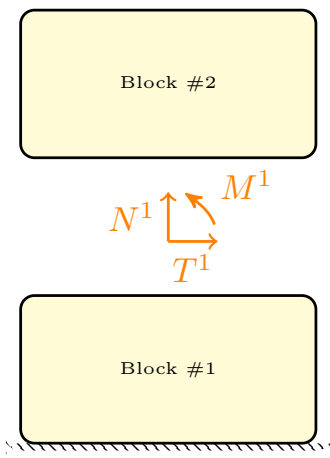

(c) static variables

FIG. 2: Schematic representation of a two-block structure with one joint represented in the local reference system

the force $f_{\star j}^{i}$ with $j=1,2$ and, the moment $m_{\star}^{i}$ applied to $i^{\text {th }}$ block. The global load

The vector $\boldsymbol{u}^{i}=\left\{u_{1}^{i}, u_{2}^{i}, \theta^{i}\right\}^{T}$, that contains the displacement components $u_{1}, u_{2}$, and the rotation $\theta$ (Figure $2 \mathrm{~b}$ ), represents the generalized displacement of the centre of the block. As previously, we define the collection of all single vector of generalized displacement in a global vector $\boldsymbol{u}$, which corresponds in the virtual work sense to the

Over each $j^{\text {th }}$ joint in that the contact surfaces between blocks is represented in the local system (Figure 2), we introduce the generalized stress and strain measures $\boldsymbol{\sigma}^{j}$

The static variables $\boldsymbol{\sigma}^{j}=\left\{N^{j}, T^{j}, M^{j}\right\}^{T}, j=1, \ldots, m$, are the internal forces acting at each $j^{\text {th }}$ joint, where $N^{j}, T^{j}$ and $M^{j}$ are the components of the normal, shear force and the moment, respectively. The collection of the local generalized stress

The kinematic variables, or generalized strain, are the relative displacement rates at joints, that is normal displacement $\xi^{j}$, tangential displacement $\gamma^{j}$ and rotation $\chi^{j}$. For each joint $j=1, \ldots, m$ they are collected in the vector $\boldsymbol{\epsilon}^{j}=\left\{\xi^{j}, \gamma^{j}, \chi^{j}\right\}^{T}$. The vector $\epsilon$ refers to the whole structure and corresponds in a virtual work sense to the vector of

Within the framework of the holonomic perfect plasticity, the following relations govern the problem of a non-standard rigid-plastic discrete material. The kinematic compatibility and the equilibrium equations for the whole system are expressed as follow:

$$
\begin{array}{r}
\boldsymbol{\epsilon}=\boldsymbol{B} \boldsymbol{u}, \\
\boldsymbol{B}^{T} \boldsymbol{\sigma}+\boldsymbol{f}=\mathbf{0},
\end{array}
$$


where B represents the compatibility matrix defined in (Baggio and Trovalusci 2000). In case of joint $k$ with arbitrary direction between two blocks, $\boldsymbol{B}$ is constructed using the rotational matrix that maps the local joint to the global one.

The generalized yield domain of the system can be written as

$$
\boldsymbol{y}=\boldsymbol{N}^{T} \boldsymbol{\sigma} \leq \mathbf{0},
$$

where $N$ is so-called gradient matrix referred to the adopted failure surface. For each $i^{\text {th }}$ blocks, Equation (4) assumes the following form:

$$
\left\{\begin{array}{l}
y_{1}^{i} \\
y_{2}^{i} \\
y_{3}^{i} \\
y_{4}^{i}
\end{array}\right\}=\left[\begin{array}{ccc}
l^{k} / 2 & 0 & -1 \\
l^{k} / 2 & 0 & 1 \\
\tan (\phi) & -1 & 0 \\
\tan (\phi) & 1 & 0
\end{array}\right]\left\{\begin{array}{c}
N^{k} \\
T^{k} \\
M^{k}
\end{array}\right\},
$$

where $l^{k}$ is the length of $k^{\text {th }}$ joint.

The flow rule expresses the vector $\epsilon$ as a linear combination of non-negative coefficients ordered in the vector $\boldsymbol{\lambda}$, called plastic multiplier vector, and it can be written as

$$
\epsilon=M \lambda,
$$

where $M$ is matrix of the modes of failures.

Finally, the complementarity condition and the non-negative work of the live loads, which cause the collapse mechanism, must be imposed by satisfying the following equations

$$
\begin{gathered}
\lambda^{T} \boldsymbol{y}=0, \\
\boldsymbol{f}_{L}^{T} \boldsymbol{u}=1 .
\end{gathered}
$$

Resorting to the formal analogy between rigid perfectly plastic discrete systems and rigid blocks with no-tension and frictional interfaces, the collapse load for a masonry structure, under the hypothesis of proportional load with the factor $\alpha>0$, can be determined. After some algebraic manipulations, for the sake of brevity the final nonlinear and non-convex programming problem (NLNCP) is reported, that reads:

$$
\begin{aligned}
\alpha_{C}= & \min \{\alpha\} \text { subjected to } \\
& \left(\boldsymbol{A} \boldsymbol{M}_{1}-\boldsymbol{M}_{2}\right) \boldsymbol{\lambda}=0, \text { kinematic compatibility } \\
& \left(\boldsymbol{A}_{0} \boldsymbol{N}_{1}^{T}\right)\left(\boldsymbol{f}_{0}+\alpha \boldsymbol{f}_{L}\right)+\left[\boldsymbol{N}_{2}^{T}-\left(\boldsymbol{A} \boldsymbol{N}_{1}\right)^{T}\right] \boldsymbol{\sigma}_{2} \leq 0, \text { static admissibility } \\
& \boldsymbol{\lambda}^{T}\left(\boldsymbol{A}_{0} \boldsymbol{M}_{1}\right)^{T} \boldsymbol{f}_{L}-1=0, \text { normalized positive work of live loads } \\
& \boldsymbol{\lambda}^{T}\left\{\left(\boldsymbol{f}_{0}+\alpha \boldsymbol{f}_{L}\right)+\left[\boldsymbol{N}_{2}^{T}-\left(\boldsymbol{A} \boldsymbol{N}_{1}\right)^{T}\right] \boldsymbol{\sigma}_{2}\right\}=0, \text { complementarity condition }
\end{aligned}
$$

where $\alpha_{C}$ is the collapse multiplier, $\boldsymbol{B}_{1}$ is the kinematical submatrix of maximum rank of the compatibility matrix $\boldsymbol{B}$ and $\boldsymbol{B}_{2}$ the rest of the kinematical matrix. The matrix 
$\boldsymbol{A}_{0}$ is the inverse of $\boldsymbol{B}_{1}$. The matrix $\boldsymbol{A}$ is defined as $\boldsymbol{A}=\boldsymbol{B}_{2} \boldsymbol{B}_{1}^{-1}$ and $\boldsymbol{N}_{i}$, with $i=1,2$, are two submatrices of $\boldsymbol{N}$ obtained after sharing the kinematical variables into two parts: the independent and the linear dependent ones (Baggio and Trovalusci 2000).

The unknowns of the problems are: $\alpha, \boldsymbol{\sigma}_{2}, \boldsymbol{\lambda}$ with the bounds $\alpha \geq 0$ and $\boldsymbol{\lambda} \geq \mathbf{0}$; $\sigma_{2}$ are the undetermined unknown of the system which represent the statically undetermined term of the generalized stress $\boldsymbol{\sigma}$ (Baggio and Trovalusci 1998).

For systems with non-associated flow rules the Drucker stability postulate no longer holds, the solution loses its uniqueness and lower/upper bounds for the collapse multipliers can be found (Drucker 1953; Radenkovic 1961). The solution of a non-linear and non-convex programming problem could not exist and when it is found, it can be locked in a local minimum rather than the global one (Kirsch 1993).

In order to deal with the NLNCP, authors (Baggio and Trovalusci 2000) developed a specific computational code (ALMA: Analisi Limite Murature Attritive), based on a two-step procedure: initially a linear programming problem (LP), obtained by adopting the assumption of dilatancy, hypothesis which makes the problem governed by associative flow rule, is solved, followed by the attempt to approach the non-linear solution using as initial guess of NLNCP the solution previously obtained for such LP.

As the solutions obtained following the dilatancy assumption approach LP (first step), which in most cases provided results frequently quite close to the solutions of NLCP (second step), both in terms of collapse multipliers and mechanisms (Baggio and Trovalusci 2000), in this work we decided to focus on the linear programming optimization problem referred as the upper bound approach of Limit Analysis, for providing collapse multipliers and the corresponding collapse mechanisms of analysed structures. It is known that when normality rule holds the static and kinematic theorems of Limit Analysis can be considered as two dual problems of linear programming optimization, which lead to a unique solution. In particular, the adopted kinematic upper bound problem is defined as

$$
\begin{aligned}
\alpha_{c}= & \min \left\{-\boldsymbol{\lambda}^{T}\left(\boldsymbol{A}_{0} \boldsymbol{N}_{1}\right)^{T} \boldsymbol{f}_{0}\right\} \text { subjected to } \\
& \left(\boldsymbol{A} \boldsymbol{N}_{1}-\boldsymbol{N}_{2}\right) \boldsymbol{\lambda}=\mathbf{0}, \text { compatibility condition } \\
& \boldsymbol{\lambda}^{T}\left(\boldsymbol{A}_{0} \boldsymbol{N}_{1}\right)^{T} \boldsymbol{f}_{L}-1=0, \text { normalized positive work of live loads }
\end{aligned}
$$

with the bounds on the unknowns $\boldsymbol{\lambda} \geq \mathbf{0}$.

\section{DESIGN OF EXPERIMENTS (DOE)}

As the aim of this work was to objectively determine the influence of various geometrical and mechanical parameters on the collapse multiplier and collapse mechanism of a masonry panel, a systematic methodology has been implemented. A general full factorial design was used to identify both the main and the two-way interaction effects of these parameters on the masonry panels response. The factors considered and their correspondent levels (in this context, a level refers to a particular value adopted by a parameter) are presented in Table 1. 
Three levels were adopted for the panel ratio factor, namely, 2:1, 1:1 and 1:2, keeping the length of the panels fixed, at a value of $B=1440 \mathrm{~mm}$, and varying their heights. These panel ratios correspond to the ones studied by (Baraldi et al. 2018), and are considered to be representative from typical masonry panels ratios present in historical buildings. The different panel ratios studied are presented in Figure 3.

Regarding the block ratio factor, three different levels were assumed: 4:1, 2:1 and 1:1, being this time the block's height the fixed value and their length the varying dimension. Block ratios of 4:1 and 2:1 are typically found both in historical and modern masonry typologies. Even if blocks with a 1:1 block ratio are rarely found in masonry buildings, this ratio has been also considered, thus enhancing the comparison purpose of this work

The different bond types studied in this work were: running (R), flemish (F), english (E) and stack (S) (see Figure 4). Running, english and flemish are implemented both as coating and for structural purposes, due to their relative higher resistance created by the good interlocking generated by the offset of their blocks, whereas the stack bond type is generally used only as coating.

Mathematically speaking the values that could be adopted for the friction angle, $\phi$, could lay within the interval $0<\phi<90$ (in degrees). Masonry friction angles have been experimentally determined by several researchers in the past and the values reported oscillate between the 17 and the 63 degrees (Rahman and Ueda 2014). However, most commonly friction angle values for historical masonry vary between 15 and 45 degrees. Therefore, the different levels for the friction ratio, $\tan (\phi)$, studied were $0.27,0.60$ and 1.00 which correspond to 15,30 and 45 degrees, respectively. The lower friction adopted would represent a situation in which the blocks surface were relatively smooth, whereas that a rough surface would be better represented by the higher friction value assumed. Finally, the adopted value of 0.60 would correspond to an intermediate level of block surface roughness.

Other important simulation parameters adopted in this work correspond to the thickness of the panels, which was assumed to be fixed for all panels at a value of $120 \mathrm{~mm}$, an also constant specific weight of $18 \mathrm{kN} / \mathrm{m}^{3}$ was assumed throughout the performed simulations as well as a null value for cohesion. The load condition applied in all simulations consisted of a self-weight (dead load) and a horizontal body force (live load) proportional to the self-weight. In summary, the full factorial DOE resulted in the simulation of 108 different masonry panels.

The basic principles of statistical study require to perform multiple experiments because the order in which they are run, the number of times they are run or the way in which they are grouped may affect the answer obtained. This is usually the case when laboratory experiments are performed as the response can be influenced by uncontrolled factors. 
TABLE 1: Factors and their respective levels.

\begin{tabular}{lll}
\hline Factor & Level & Value \\
\hline A. Panel ratio (length:height) & $1.2: 1$ & $1440 \times 720 \mathrm{~mm}$ \\
& $2.1: 1$ & $1440 \times 1440 \mathrm{~mm}$ \\
& $3.1: 2$ & $1440 \times 2880 \mathrm{~mm}$ \\
B. Block ratio (length:height) & $1.4: 1$ & $240 \times 60 \mathrm{~mm}$ \\
& $2.2: 1$ & $120 \times 60 \mathrm{~mm}$ \\
& $3.1: 1$ & $60 \times 60 \mathrm{~mm}$ \\
C. Bond type & 1. Running & - \\
& 2. Flemish & - \\
& 3. English & - \\
& 4. Stack & - \\
D. Friction $(\tan (\phi))$ & 1. Low & 0.27 \\
& 2. Medium & 0.60 \\
& 3. High & 1.00 \\
\hline
\end{tabular}

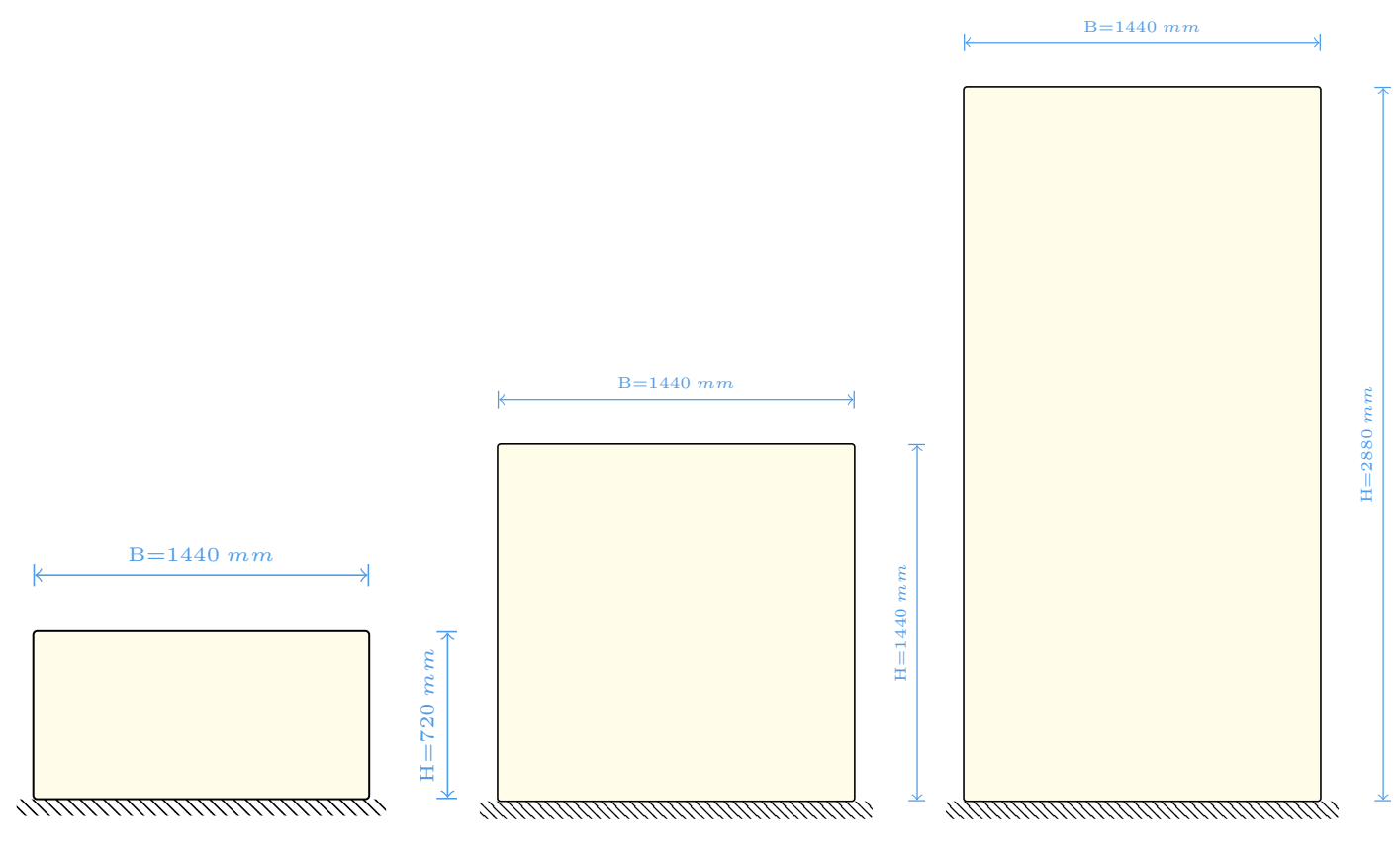
(a) Panel ratio $\mathrm{B} / \mathrm{H}=2: 1$
(b) Panel ratio $\mathrm{B} / \mathrm{H}=1: 1$
(c) Panel ratio $\mathrm{B} / \mathrm{H}=1: 2$

FIG. 3: Masonry panels with the different ratios adopted for the analysis. 


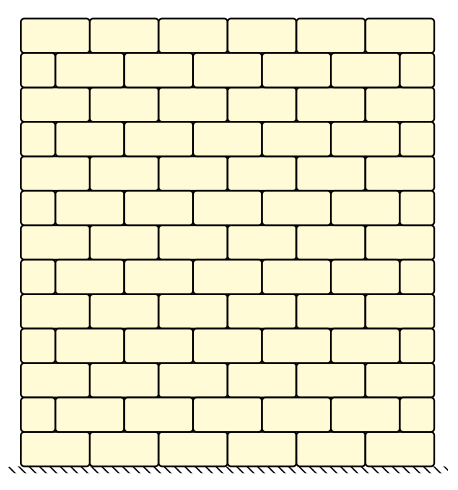

(a) Running

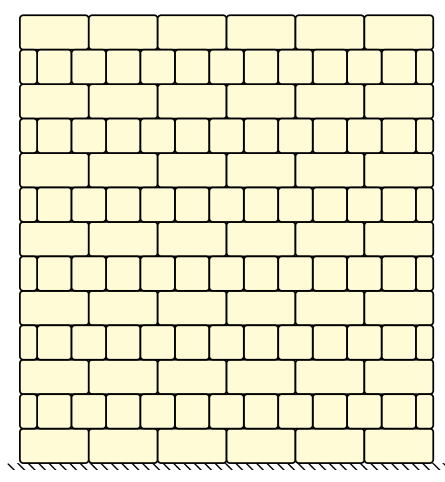

(c) English

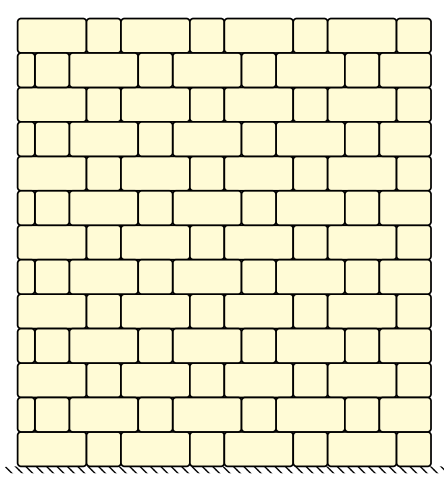

(b) Flemish

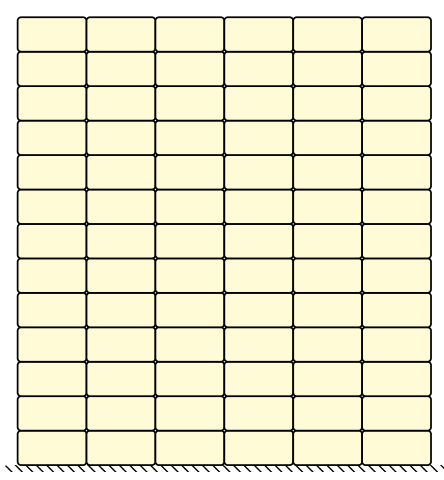

(d) Stack

FIG. 4: Masonry panels with the different bond types tested.

After all simulations were successfully run, the responses (collapse multipliers) obtained were visually analysed by the averages of main effects and two-way interaction effects plots. The main effect plots allow to see the actual effect that every single parameter has in the response. By computing the average values at every level of each parameter it is assumed that the response is independent of the other parameters. On the other hand, two-way (or higher order) interaction plots allow to study the possible interaction between two (or more) parameters and how this affects the response. The points of a two-way interaction plot are computed by averaging the values of $\alpha$ obtained for a certain combination of two parameters' levels.

Furthermore, the collapse multipliers obtained were formally analysed through an analysis of variance (ANOVA). The ANOVA, sometimes referred to as significance of regression test, determines whether there is a relationship between the parameters of the statistical model (also known as regressor variables) and the response. The hypotheses of the ANOVA test are:

$$
\begin{aligned}
& H_{0}: \beta_{1}=\beta_{2}=\ldots \beta_{k}=0, \\
& H_{1}: \beta_{j} \neq 0 \text { for at least one } j .
\end{aligned}
$$


Where $H_{0}$ and $H_{1}$ are the null and the alternative hypothesis respectively, and $\beta_{j}$ represents every coefficient of the linear and two-way interaction terms of the statistical model adopted. The rejection of $H_{0}$ implies that at least one of the terms contributes significantly to the output of the statistical model. The statistical model adopted for the masonry panels is composed by four linear terms (panel ratio, block ratio, bond type and friction), six two-way interaction terms (combinations of the four linear terms previously mentioned) and an error term. Linear terms correspond to the effect that individual parameters have in the response whereas that two-way interaction terms depict how the response is affected by a certain parameter in combination with the different levels of a second one. The error term is related to the inherent variation of the model and is assumed to be normally and independently distributed.

Further details about the statistical approach adopted and the ANOVA analysis are reported in Appendix A. Additionally, the magnitude and importance of each one of the main factors and factor interaction effects were obtained. Those results are presented as Pareto charts of standardized effect. The Pareto chart of standardized effects is used to compare the relative magnitude and the statistical significance of the main parameters and of the two-way interaction terms in the response. Moreover, a reference line is also plotted in the Pareto chart in order to simplify the identification of the significant terms (every term with a standardized effect value higher than the reference line is considered to be statistically significant).

The suitability of the adopted statistical model to describe the response, which is basically a regression model, was measured as the values of the coefficient of determination, $R^{2}$ (equal to the regression sum of squares divided by the total sum of squares), and of the predicted coefficient of determination, $R_{p r e d}^{2}$. Finally, the assumptions that the data was independent and normally distributed, in other words, that the analysed data was not affected by non-controlled parameters and that it roughly presents the shape of the Gauss curve, were visually validated by analysing the standardized residual plots of the response, $\alpha$, its histogram and its normal probability plot.

\section{RESULTS AND DISCUSSION}

After running the 108 different simulations generated with the adopted DOE, results were obtained in terms of collapse multiplier values and collapse mechanisms.

Focusing our attention first on the analysis of the collapse multipliers, Table 5, in Appendix B, presents the collapse multipliers obtained for every simulation. Figure 5 presents the main effects plot for the response, $\left\langle\alpha_{c}\right\rangle$, in which the effect that every single parameter studied has in the response can be observed. Each curve corresponds to one of the factors considered in this study. For instance, the left graph of Figure 5 provides mean $\left\langle\alpha_{c}\right\rangle$ values obtained while the variation of the rest of parameters is neglected. In this context, to study the effect that the panel ratio parameter has in the response it is necessary to compute the mean response at each one of its levels, namely, 2:1, 1:1 and 1:2. From Table 5 it can be observed that a value of panel ratio equal to 2:1 was implemented in a total of 36 simulations. Thus, the mean response value is computed as the average of the 36 corresponding collapse multipliers. This mean value is plotted as the point corresponding to a panel ratio of $2: 1$ in the leftmost 
curve of Figure 5. Similarly, mean response values were computed and plotted for panel ratio values of 1:1 and 1:2, as well as for the rest of levels of each individual parameter studied in this paper.
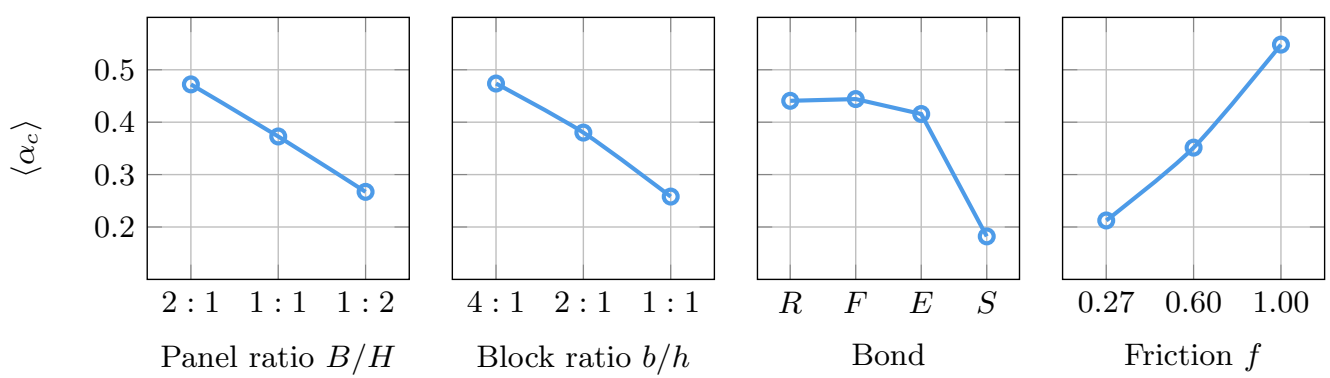

FIG. 5: Variation of mean value $\left\langle\alpha_{c}\right\rangle$ fixing one analysis parameters and varying the others.

It can be clearly noticed that all factors significantly influence the values of $\left\langle\alpha_{c}\right\rangle$. There is a direct correspondence between the values of $\left\langle\alpha_{c}\right\rangle$ and panel ratio and block ratio values, in the sense that the more slender the panel/brick the lower is the value of the collapse multiplier. Differently, it can be observed that the higher the friction coefficient, the grater the value of $\left\langle\alpha_{c}\right\rangle$.

A clear different response can be identified in therms of the bond type. While running, english and flemish bond types present similar average values of $\left\langle\alpha_{c}\right\rangle$, the stack bond type shows a relatively low value for the average collapse multiplier. This is without a doubt the result of the lack of units interlocking of the stack masonry panels simulated as shown in (Baraldi et al. 2018). After further analysing the bond type main effect, by the means of a Tukey's multi comparison confidence intervals, it was observed that there was effectively a significant difference between the mean collapse multipliers of the stack bond panels and the other types of bond, but not between running, english and flemish bond mean collapse multipliers. This fact may justify a modelling geometry simplification when in real historic masonry structures it is not possible to fully observe masonry texture, i.e. when the wall is partially rendered.

Furthermore, interesting information can be drawn from the observation of the response interaction plots presented in Figure 6. In this figure different plots, corresponding to the interaction of every pair of main factors analysed in this study, are organized and presented as a lower matrix. 

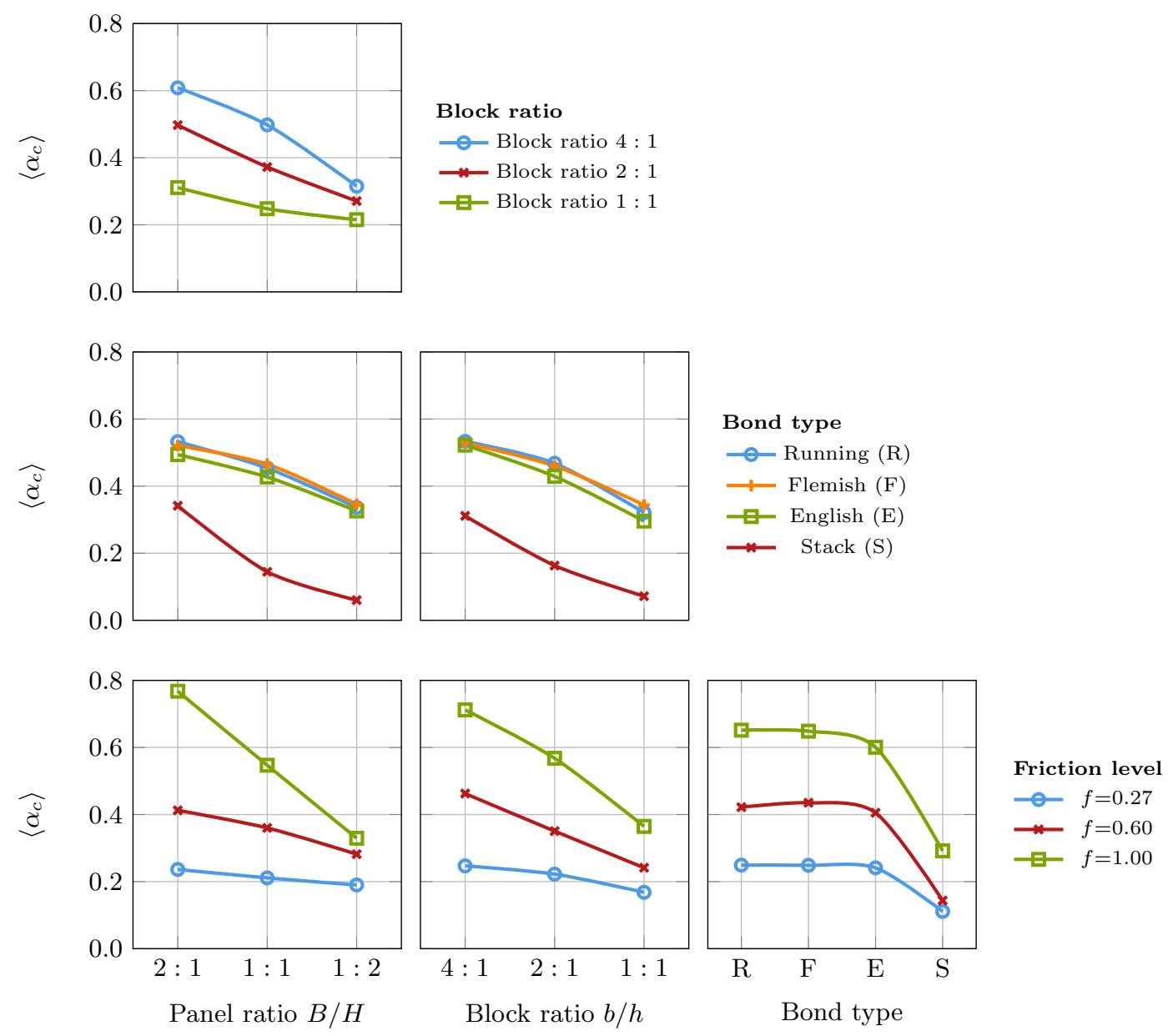

FIG. 6: Interaction plot for $\left\langle\alpha_{c}\right\rangle$.

In fact, this matrix is symmetric and the upper part has been omitted for the sake of clarity. In every plot a specific factor level has been plotted against the mean value of $\left\langle\alpha_{c}\right\rangle$, and the different curves in every plot correspond to the different levels of the second main factor indicated in the legend at the right side of Figure 6. From these plots, it can be observed that a significant correlation exist between the studied interaction factors and the response of the different masonry panels. Regarding the Panel*Block interaction plot it can be seen that slender panels (1:2 ratio) always produce lower mean values of $\left\langle\alpha_{c}\right\rangle$ in comparison with square (1:1 ratio) and squat panels (2:1 ratio). Moreover, for the different levels of block ratio it can be observed that the more slender the block (1:1 ratio) the lower would be the values of the response. These observations are in agreement with results obtained from other parametric analysis (Bustamante 2003; Casapulla and Argiento 2018). If the Panel*Friction and the Block*Friction plots are analysed, it is clear that higher values of friction would give a higher strength to the panel and result into higher collapse multiplier values. Furthermore, from these three plots a wider variation on the response can be noticed for the squat panel/block ratios in comparison with the slender levels of those factors. This indicates that the influence of 
block ratio and friction ratio in the response of squat panels would be more significant than in the response of slender panels where the response would be mainly influenced by the geometry of the panel itself.

Analogously as it was observed in the main effects plots, the response obtained for the english, flemish and running bonds was quite similar, whereas that a clear lower response is obtained for the stack bond panels simulated. The Panel*Bond and the Block*Bond plots follow the tendencies previously described. Since the bond type factor is a categorical factor, no clear trend can be drawn from the Bond*Friction plot except for the fact that at every factor levels combination, the stack bond resulted into lower values of $\alpha_{c}$ in comparison with the other bond types. As per the main effects plots, it can be said that a significant interaction exists between bond type and the rest of the factors if the stack bond is included. On the other hand, no interaction would be observed if only the running, english and flemish bonds were considered.

These visual assumptions are formally verified through an analysis of variance (ANOVA) test of the results. Table 2 presents the ANOVA results performed using the software Minitab ${ }^{\circledR}$ (https://www.minitab.com/en-us/). In the first column of Table 2 the statistical model terms are identified by their names, in the second column the degrees of freedom (DoF) of every term are presented, in the third column the adjusted sum of squares (Adj SS) corresponding to every term are shown and in column four the adjusted mean squares (Adj MS) are listed. In the fifth column of the ANOVA table we can see the value corresponding to the $F$ statistical test and finally, in the last column of Table 2, the corresponding P-Values to each term are presented.

From Table 2 it can be observed from the P-Values of the ANOVA table that besides from the Block*Bond, all linear and two-way interactions are statistically significant $(P-$ Value $<0.05)$ at a confidence level of $95 \%$. 
TABLE 2: ANOVA.

\begin{tabular}{llllrl}
\hline Source & DoF & Adj SS & Adj MS & F-Value & P-Value \\
\hline Model & 39 & 6.0529 & 0.1552 & 51.98 & 0.000 \\
$\quad$ Linear & 9 & 4.9403 & 0.5489 & 183.86 & 0.000 \\
$\quad$ Panel & 2 & 0.7573 & 0.3787 & 126.83 & 0.000 \\
Block & 2 & 0.8426 & 0.4213 & 141.12 & 0.000 \\
Bond & 3 & 1.2930 & 0.4310 & 144.37 & 0.000 \\
$\quad$ Friction & 2 & 2.0474 & 1.0237 & 342.88 & 0.000 \\
Two-Way Interactions & 30 & 1.1126 & 0.0371 & 12.42 & 0.000 \\
$\quad$ Panel*Block & 4 & 0.1347 & 0.0337 & 11.28 & 0.000 \\
$\quad$ Panel*Bond & 6 & 0.0658 & 0.0110 & 3.67 & 0.003 \\
$\quad$ Panel*Friction & 4 & 0.5117 & 0.1279 & 42.85 & 0.000 \\
Block*Bond & 6 & 0.0234 & 0.0039 & 1.31 & 0.266 \\
$\quad$ Block*Friction & 4 & 0.2203 & 0.0551 & 18.45 & 0.000 \\
Bond*Friction & 6 & 0.1566 & 0.0261 & 8.74 & 0.000 \\
Error & 68 & 0.2030 & 0.0030 & & \\
Total & 107 & 6.2559 & & & \\
\hline
\end{tabular}

DoF=Degrees of freedom, Adj SS= Adjusted sum of squares, Adj MS = Adjusted mean of squares.

Furthermore, the magnitude and importance of each one of the main factors and factor interaction effects were obtained. Figure 7 presents the Pareto chart of standardized effect. The Pareto chart of standardized effects is used to compare the relative magnitude and the statistical significance of the main parameters and of the two-way interaction terms in the response. Moreover, in Figure 7 a reference line is also plotted in order to simplify the identification of the significant terms (every term with a standardized effect value higher than the reference line is considered to be statistically significant).

In Figure 7 it can be seen that all main factors as well as the Panel*Friction interaction would have a bigger effect on the response of the masonry panels. These are followed in order of importance by the Block*Friction, the Panel*Block, the Bond*Friction and the Panel*Bond interaction effects. Finally, it can be observed that the standardized effect of the Block*Bond interaction is smaller than the reference value, in this case 1.995 , and therefore is not considered to be statistically significant.

Regarding the suitability of the adopted statistical model to describe the response, the values of the coefficient of determination, $R^{2}$ (equal to the regression sum of squares divided by the total sum of squares), and of the predicted coefficient of determination, $R_{\text {pred }}^{2}$, obtained were of $96.75 \%$ and $91.81 \%$ respectively. This proves the good fit and the high prediction capabilities of the model adopted. Nevertheless, the statistical model could be further improved if a new statistical model were performed 
without considering the Block*Bond interaction term, but that step is outside the scope of this work.

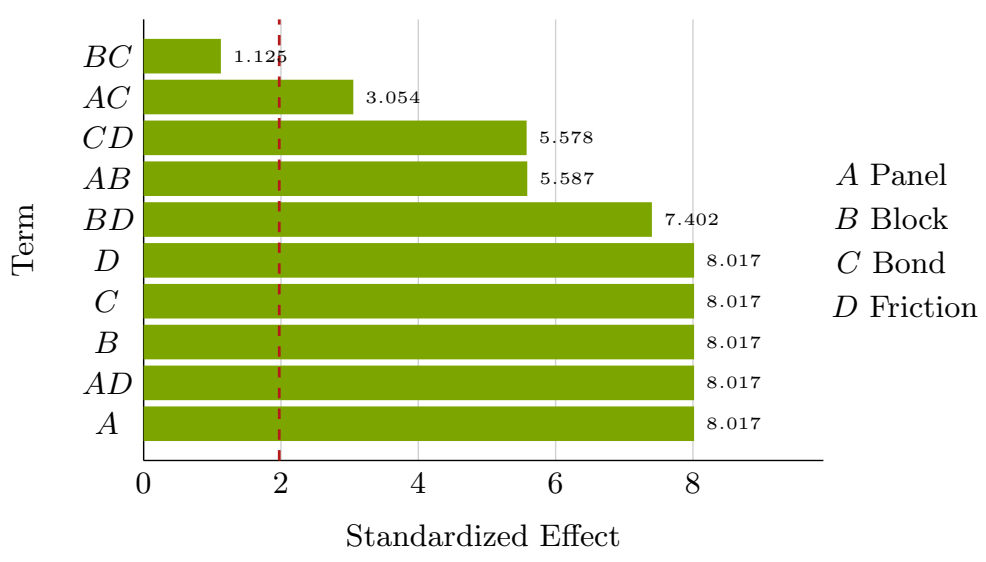

FIG. 7: Pareto chart of the standardized effects: magnitude and importance of the different main factors and factor interactions effects.

The statistical analysis performed was carried out under the assumption that the data was independent and normally distributed, in other words, that the analysed data was not affected by non-controlled parameters and that it roughly present the shape of the Gauss curve. These assumptions were visually validated by analysing the standardized residual plots of the response, $\alpha_{c}$, its histogram and its normal probability plot. In the normal probability plot of Figure 8 (upper right plot) it could be observed that most of the points were relatively close to the diagonal line. There was only one standardized residual with a value larger than three, which represented an outlier, that did not influence significantly the suitability of the adopted model. Furthermore, if this point were disregarded it could be observed that the histogram on Figure 8 resembled to a Gauss distribution and that no clear structure is present on the Versus Fits nor on the Versus order plots of the standardized residuals in Figure 8. 

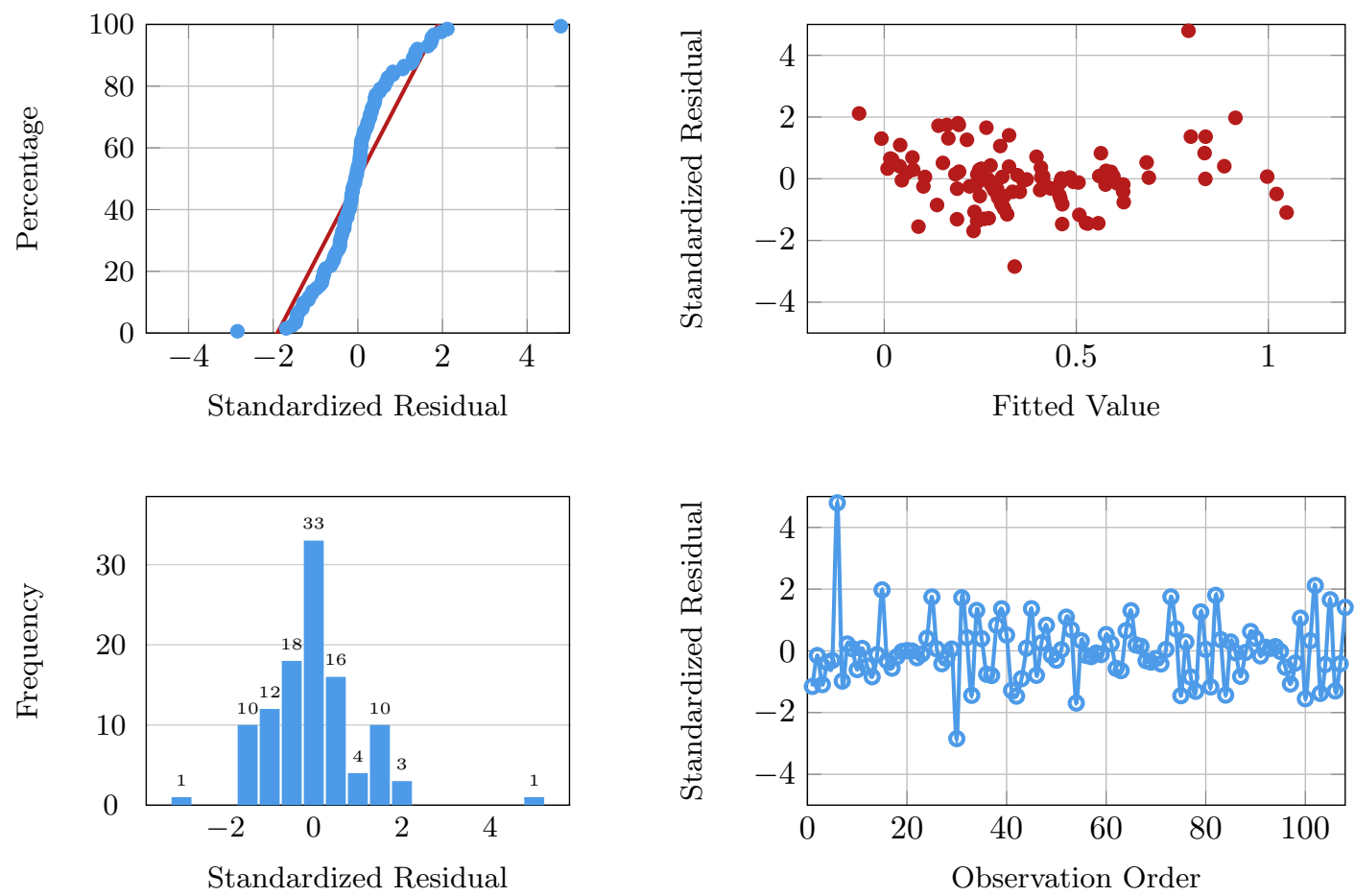

FIG. 8: Normal probability, histogram and standardized residual plots.

Although not explicitly included as one of the main factors in the DOE presented in this paper, the scale factor, meaning the ratio between block and panel dimension, could as well be analysed based on the results obtained. Figure 9 presents the mean values of $\left\langle\alpha_{c}\right\rangle$ obtained as a function of the scale factor, $\mathrm{H} / \mathrm{b}$, for running (Figure 9(left)), english (Figure 9(center)) and flemish (Figure 9(right)) bond panels at different values of friction coefficient. In the group of performed analysis all of those with the same scale ratio $H / b$ at fix bond type and level of friction coefficient have been selected for computing the mean value of $\left\langle\alpha_{c}\right\rangle$.

By comparing the plots, it can be observed that the panels response for the three type of textures well interlocked, R, F, E, is not affected by the choice of bond, same values of $\alpha_{c}$ were obtained for the three bond types, while for the stack bond panels lower collapse multiplier values are detected. Friction has greater influence for low value of ratio $\mathrm{H} / \mathrm{b}$ and decreases as panel became slender. 

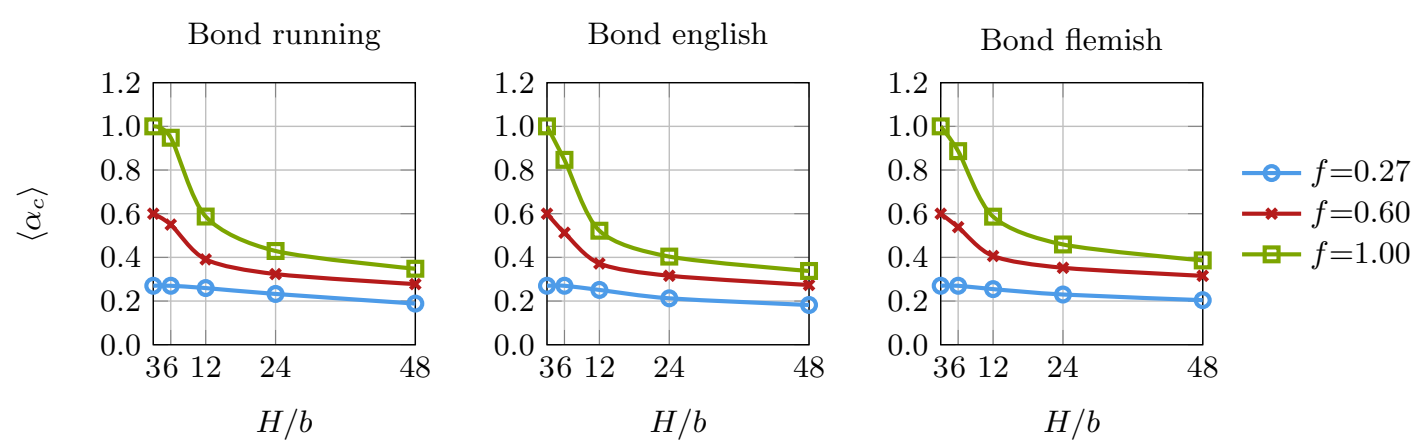

FIG. 9: Variation of the mean value of collapse multiplier $\left\langle\alpha_{c}\right\rangle$ vs the scale factor, $H / b$, for different friction ratios, $f=\tan (\phi)$.

A similar trend may be observed considering scale factor $\mathrm{B} / \mathrm{b}$. In Figure 10 presents the mean values of $\left\langle\alpha_{c}\right\rangle$ obtained as a function of the scale factor, $\mathrm{B} / \mathrm{b}$, for different panel ratio at different values of friction coefficient. It can be observed that at low friction levels the panel and the scale factor are both negligible as the panel response is mostly influenced by friction. For the case of slender panels $(\mathrm{B} / \mathrm{H}=0.5)$ the scale factor seems to play a minor role on the average collapse multiplier values. On the other hand, for intermediate and high friction values (0.6 and 1.0 respectively), and panel ratios $\mathrm{B} / \mathrm{H}=1$ and $\mathrm{B} / \mathrm{H}=2$, an interaction effect can be observed where at lower scale factor, higher values of $\alpha_{c}$ are obtained.

Panel $\mathrm{B} / \mathrm{H}=2$

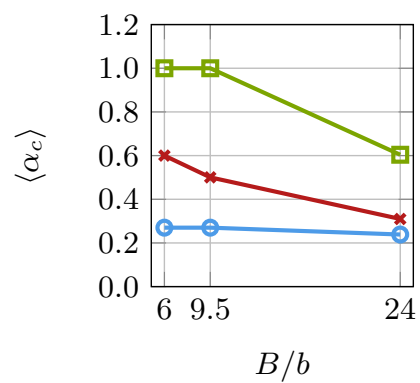

Panel $\mathrm{B} / \mathrm{H}=1$

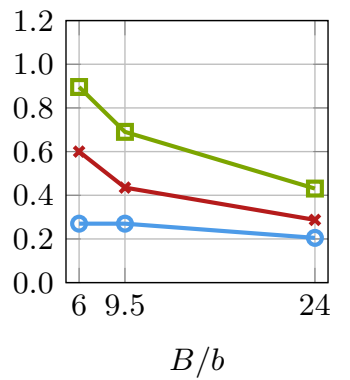

Panel $\mathrm{B} / \mathrm{H}=0.5$

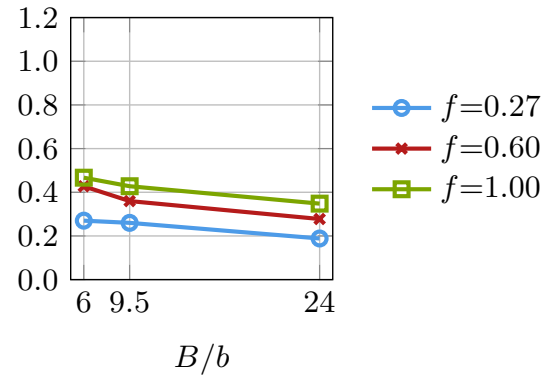

FIG. 10: Variation of the mean value of collapse multiplier $\left\langle\alpha_{c}\right\rangle$ vs the scale factor $B / b$ for different friction coefficient: (left) Panel ratio $\mathrm{B} / \mathrm{H}=2$, (center) Panel ratio $\mathrm{B} / \mathrm{H}=1$ and (right) Panel ratio $\mathrm{B} / \mathrm{H}=0.5$.

Focusing our attention now on the failure type presented by the different masonry panels simulated, the collapse mechanism of each panel was also plotted and qualitatively analysed. Considering a texture with high level of interlocking, which tends to behave as a monolithic assembly, in terms of collapse mechanism two different outcomes are detected: 1) a sliding mechanism for the squat panels and 2) a rotation mechanism for slender panels. From the results obtained in this parametric analysis 


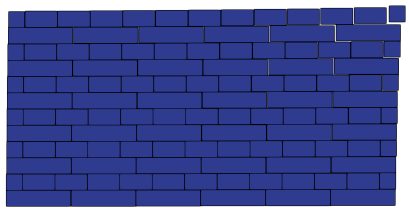

(a) Panel ratio 2:1, $\alpha_{c}=0.6000$

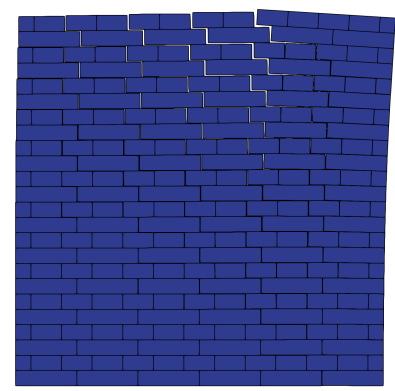

(b) Panel ratio 1:1, $\alpha_{c}=0.5636$

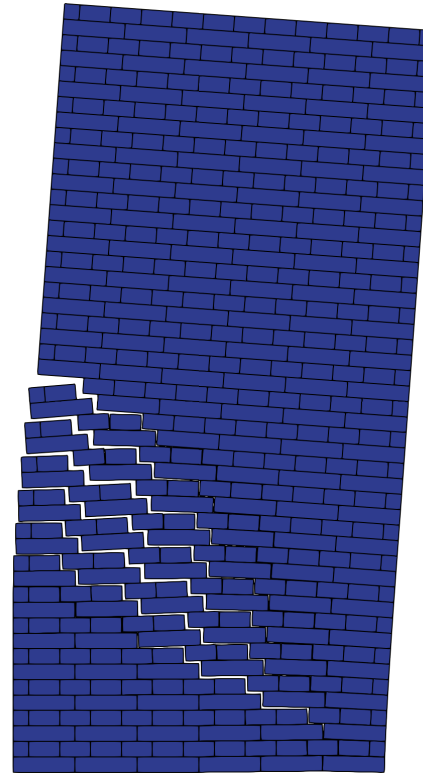

(c) Panel ratio 1:2, $\alpha_{c}=0.4108$

FIG. 11: Collapse mechanisms of english panels with friction coefficient $f=0.60$ and block ratio 4:1 flemish panel with ratio 1:2 and friction coefficient equal to 0.6. Analysing different 


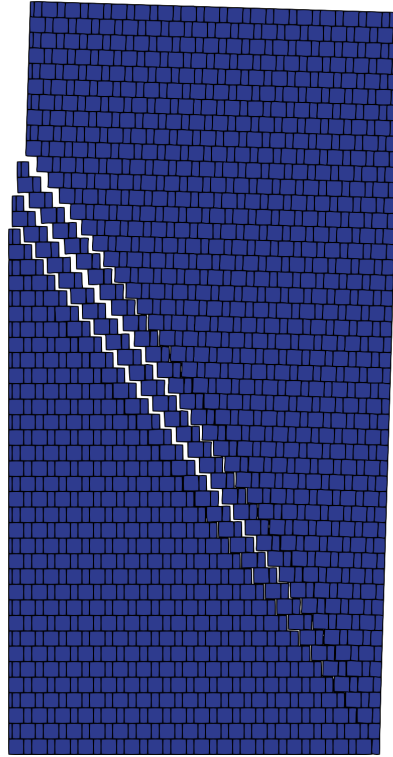

(a) Block ratio 1:1, $\alpha_{c}=0.3155$

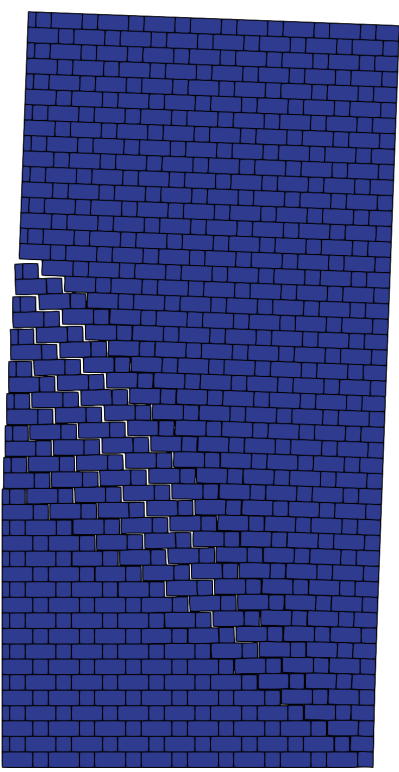

(b) Block ratio 2:1, $\alpha_{c}=0.3699$

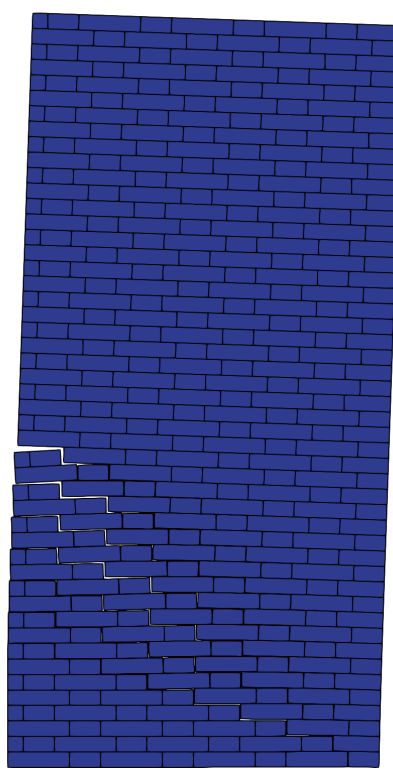

(c) Block ratio 4:1, $\alpha_{c}=0.4236$

FIG. 12: Collapse mechanisms of Flemish panels with panel ratio 1:2 and medium value of friction, $f=0.60$

In Figure 13 the collapse mechanisms for running panels with panel ratio 1:1 and low level of friction have been shown. In this case the same trend between block ratio and collapse multiplier is obtained. In particular a rotational mechanism is obtained for the low value of block ratio (Figure 13a) and sliding mechanisms for the other two level of block ratio (Figure 13b and Figure 13c). 


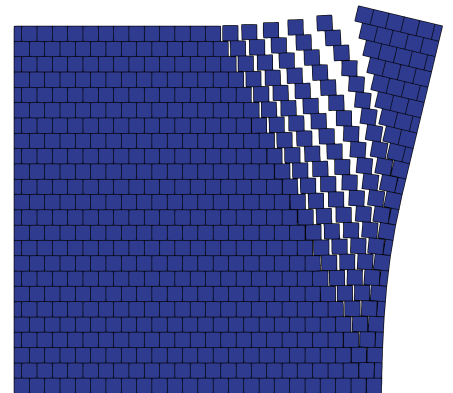

(a) Block ratio 1:1, $\alpha_{c}=0.2049$

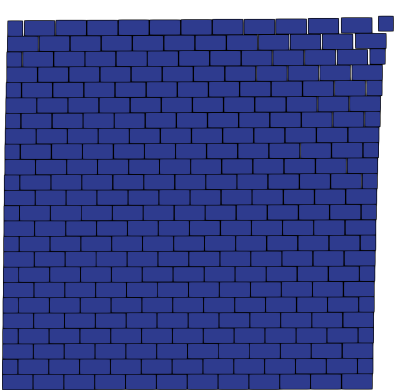

(b) Block ratio 2:1, $\alpha_{c}=0.2670$

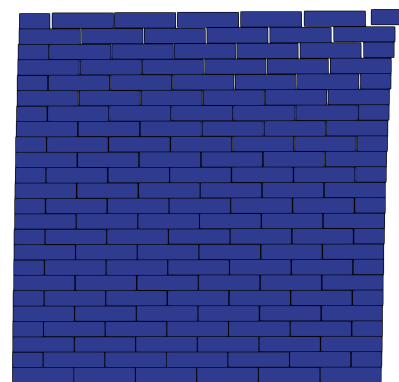

(c) Block ratio 4:1, $\alpha_{c}=0.2670$

FIG. 13: Collapse mechanisms of Running panels with panel ratio 1:1 and low value of friction, $f=0.27$

Collapse mechanisms of english panels with ratio 1:1 and block ratio 2:1 at different values of friction are shown in Figure 14. A relationship between the friction coefficient and the collapse multiplier is evident in Figure 14.

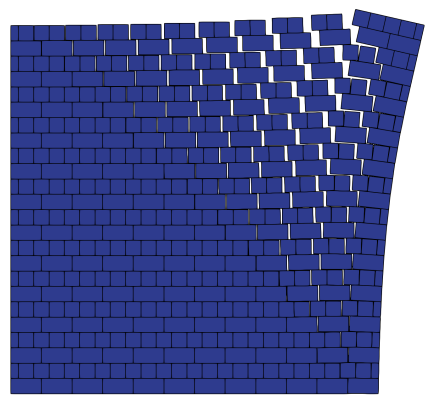

(a) Friction $f=0.27$
$\alpha_{c}=0.2670$

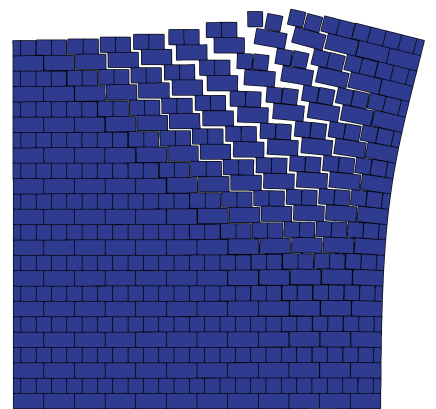

(b) Friction $f=0.60$, $\alpha_{c}=0.4097$

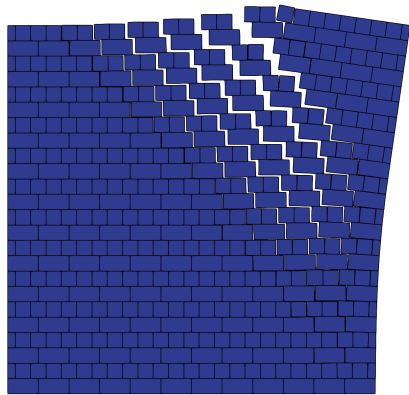

(c) Friction $f=1.00$, $\alpha_{c}=0.6142$

FIG. 14: Collapse mechanisms of English panels with panel ratio 1:1 and block ratio 2:1

Finally, in Figure 15 the collapse mechanisms of panels with panel and block ratio equal to $2: 1$ and friction $f=0.60$ for different bond type have been reported. 




(a) Bond running, $\alpha_{c}=0.5006$

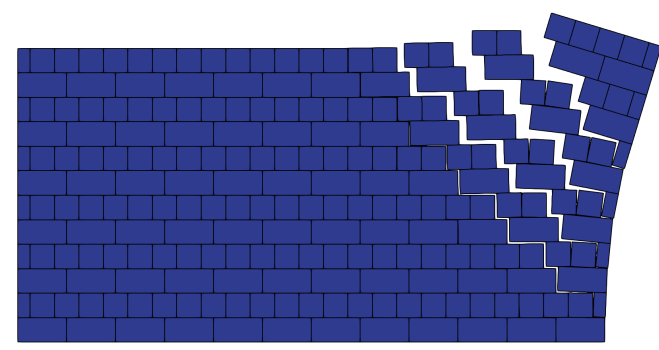

(c) Bond english, $\alpha_{c}=0.4620$

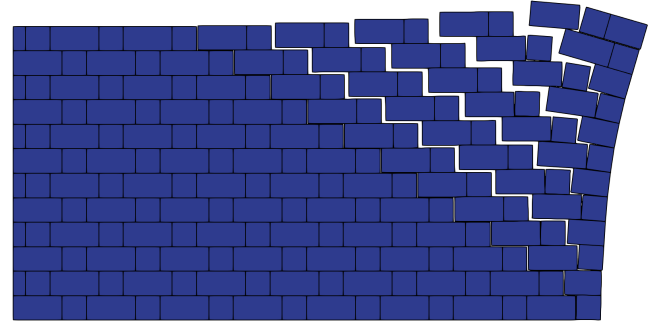

(b) Bond flemish, $\alpha_{c}=0.4883$

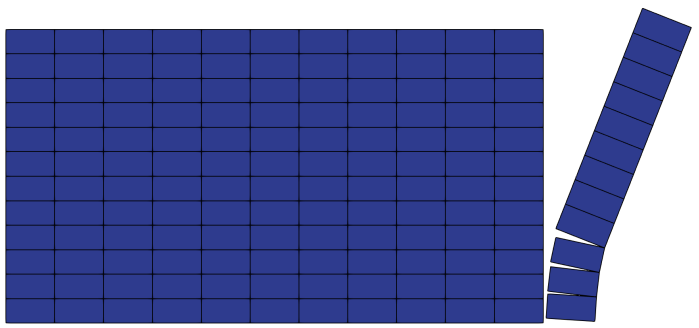

(d) Bond stack, $\alpha_{c}=0.2245$

FIG. 15: Collapse mechanisms of panels with panel ratio 2:1, block ratio 2:1 and medium value of friction, $f=0.60$

The different steps of the performed experiment and the main findings are summarized in Table 3.

TABLE 3: Parametric analysis summary.

\begin{tabular}{ll}
\hline Step & Information \\
\hline $\begin{array}{l}\text { Recognition of and statement of } \\
\text { the problem. }\end{array}$ & $\begin{array}{l}\text { What is the effect of panel ratio, block ratio, bond type } \\
\text { and friction on the collapse multiplier } \alpha_{c} \text { of a masonry } \\
\text { panel? }\end{array}$ \\
$\begin{array}{l}\text { Selection of response variable. } \\
\text { Chollapse multiplier } \alpha_{c} .\end{array}$ & $\begin{array}{l}\text { Panel ratio at } 3 \text { levels: } 2: 1,1: 1,1: 2 \\
\text { Block ratio at } 3 \text { levels: } 4: 1,2: 1,1: 1\end{array}$ \\
& $\begin{array}{l}\text { Bond type at } 4 \text { levels: Running, Stack, English, Flemish } \\
\text { Friction at } 3 \text { levels: } 0.27,0.60,1.00\end{array}$ \\
Phoice of experimental design. & Full-composite. \\
Statistical analysis of the data. & Trivial \\
\hline
\end{tabular}

\section{CONCLUSIONS}

The parametric analysis presented in this paper allowed to objectively identify the 
effect that the panel ratio, block ratio, bond type and friction ratio parameters have in the collapse multiplier value and in the collapse mechanism of a brick masonry panel using a non-standard limit analysis approach. All the analyses performed considered masonry walls made of bricks of different size and texture subjected to self-weight, the dead load, and to an horizontal body force proportional to the weight through a non negative load factor, the live load, which statically simulates a seismic action. The main findings drawn from this work are:

- There is a strong correlation between the main factors and the response.

- With the exception of Block*Bond, all two-way interactions also resulted to be statistically significant.

- The expected collapse mechanism could be modified under certain factor levels combinations.

- The collapse multiplier for a panel that presents a sliding failure type corresponds with the value of the friction ratio, $\tan (\phi)$, whereas that the collapse multiplier for panels that develop a rotation failure type would always be smaller than this ratio.

- All the analyses show the importance in the collapse behaviour of the size and the disposition of the bricks that determine the level of interlocking among bricks, and then the cohesion of the whole.

The statistical model implemented in this work could be further refined if the nonstatistically significant terms were neglected. Moreover, the results obtained from this study would be further exploited by the authors in a future work where a response surface analysis (an statistical analysis that provides a series of equations that can be used to predict the response of a model based on different levels of its input parameters) will be performed with the aim of providing a series of interpolation equations to compute the approximate collapse multiplier of a masonry panel based on a random combination of factor levels.

\section{APPENDIX A: ANOVA}

This appendix contains all details realted to the statistical approach adopted and the ANOVA analysis.

In an ANOVA context, the DoF are the amount of free data available to estimate the coefficient of every statistical term in the model. For instance, the total DoF is equal to the number of collapse multipliers obtained from the simulations minus one. Every linear term in the model as a DoF equal to their number of levels minus one. The addition of all DoF corresponding to the linear terms of the model provides the total DoF for the linear part of the model. The DoF of the interaction terms is equal to the product of the DoF from the corresponding linear terms. Similarly, the total DoF corresponding to the two-way interaction part of the model is equal to the addition of the DoF from the different two-way individual interaction terms. The DoF of the model are equal to the sum of the DoF from its linear and two-way interaction parts. Finally, the DoF that correspond to the error term of the model are equal to the total DoF 
minus the DoF of the model. For further clarification, if the levels of every parameter studied: panel ratio (A), block ratio (B), bond type (C) and friction (D), are assigned respectively with the letters $a, b, c$ and $d$, then the DoF are computed as presented in Table 4.

TABLE 4: Computation of DoF for the ANOVA.

\begin{tabular}{|c|c|}
\hline Source & DoF \\
\hline Model & $D o F_{\text {Model }}=D_{o F_{\text {Linear }}}+D_{o F_{\text {Two-WayInteractions }}}$ \\
\hline Linear & $D o F_{\text {Linear }}=D o F_{A}+D o F_{B}+D o F_{C}+D o F_{D}$ \\
\hline A & $D o F_{A}=a-1$ \\
\hline $\mathrm{B}$ & $D o F_{B}=b-1$ \\
\hline $\mathrm{C}$ & $D o F_{C}=c-1$ \\
\hline $\mathrm{D}$ & $D o F_{D}=d-1$ \\
\hline Two-Way Interactions & $\begin{array}{l}\text { DoF } F_{\text {Two-WayInteractions }}=D o F_{A B}+D o F_{A C} \\
+D o F_{A D}+D o F_{B C}+D o F_{B D}+D o F_{C D}\end{array}$ \\
\hline $\mathrm{A} * \mathrm{~B}$ & $D o F_{A B}=D o F_{A} * D o F_{B}$ \\
\hline $\mathrm{A} * \mathrm{C}$ & $D_{o} F_{A C}=D_{o} F_{A} * D o F_{C}$ \\
\hline$A * D$ & $D_{o} F_{A D}=D_{o} F_{A} * D o F_{D}$ \\
\hline $\mathrm{B} * \mathrm{C}$ & $D o F_{B C}=D o F_{B} * D o F_{C}$ \\
\hline $\mathrm{B} * \mathrm{D}$ & $D o F_{B D}=D o F_{B} * D o F_{D}$ \\
\hline $\mathrm{C}^{*} \mathrm{D}$ & $D o F_{C D}=D o F_{C} * D o F_{D}$ \\
\hline Error & $D o F_{\text {Error }}=D o F_{\text {Total }}-D o F_{\text {Model }}$ \\
\hline Total & $D o F_{\text {Total }}=a * b * c * d-1$ \\
\hline
\end{tabular}

Let $y_{i j k l}$ represent the collapse multiplier obtained for every simulation where $i$ is the level of factor $A(i=1,2 \ldots a), j$ the level of factor $B(j=1,2 \ldots b), k$ the level of factor $C(k=1,2 \ldots c)$ and $l$ the level of factor $D(l=1,2 \ldots d)$. Then, $y_{i \ldots .}, y_{. j . .}, y_{. k}$. and $y_{\ldots l}$ represent the total addition of the collapse multipliers corresponding to every level of factors $A, B, C$ and $D$ respectively. The totals for every two-way interaction are represented by $y_{i j . .}, y_{i . k .}, y_{i . . l}, y_{. j k .}, y_{. j . l}$ and $y_{. . k l}$. Finally, $y_{\ldots . . .}$ represents the grand total. 


$$
\begin{aligned}
& y_{i \ldots}=\sum_{j=1}^{b} \sum_{k=1}^{c} \sum_{l=1}^{d} y_{i j k l}, \\
& y_{. j . .}=\sum_{i=1}^{a} \sum_{k=1}^{c} \sum_{l=1}^{d} y_{i j k l} \text {, } \\
& y_{. . k .}=\sum_{i=1}^{a} \sum_{j=1}^{b} \sum_{l=1}^{d} y_{i j k l} \text {, } \\
& y_{\ldots l}=\sum_{i=1}^{a} \sum_{j=1}^{b} \sum_{k=1}^{c} y_{i j k l} \text {, } \\
& y_{i j . .}=\sum_{k=1}^{c} \sum_{l=1}^{d} y_{i j k l} \text {, } \\
& y_{i . k .}=\sum_{j=1}^{b} \sum_{l=1}^{d} y_{i j k l} \text {, } \\
& y_{i . . l}=\sum_{j=1}^{b} \sum_{k=1}^{c} y_{i j k l} \text {, } \\
& y_{. j k .}=\sum_{i=1}^{a} \sum_{l=1}^{d} y_{i j k l} \text {, } \\
& y_{. j . l}=\sum_{i=1}^{a} \sum_{k=1}^{c} y_{i j k l}, \\
& y_{. . k l}=\sum_{i=1}^{a} \sum_{j=1}^{b} y_{i j k l} \text {, } \\
& y_{\ldots .}=\sum_{i=1}^{a} \sum_{j=1}^{b} \sum_{k=1}^{c} \sum_{l=1}^{d} y_{i j k l} \text {, }
\end{aligned}
$$

For every total term in Equation 12, a average can be computed as presented in 
Equation 13.

$$
\begin{aligned}
\bar{y}_{i . .} & =\frac{y_{i . . .}}{b * c * d}, \\
\bar{y}_{. j . .} & =\frac{y_{. j . .}}{a * c * d}, \\
\bar{y}_{. . k .} & =\frac{y_{. . k .}}{a * b * d}, \\
\bar{y}_{. . . l} & =\frac{y_{. . .}}{a * b * c}, \\
\bar{y}_{i j . .} & =\frac{y_{i j . .}}{c * d}, \\
\bar{y}_{i . k .} & =\frac{y_{i . k .}}{b * d}, \\
\bar{y}_{i . . l} & =\frac{y_{i . . l}}{b * c}, \\
\bar{y}_{. j k .} & =\frac{y_{. j k .}}{a * d}, \\
\bar{y}_{. j . l} & =\frac{y_{. j . l}}{a * c}, \\
\bar{y}_{. . k l} & =\frac{y_{. . k l}}{a * b}, \\
\bar{y}_{\ldots . . .} & =\frac{y \ldots . .}{a * b * c * d},
\end{aligned}
$$

The total adjusted sum of squares is split to represent the variability for each one of the terms in the model as presented in Equation 15.

$$
\begin{array}{r}
\operatorname{adj} S S_{T}=\operatorname{adj} S S_{A}+\operatorname{adj} S S_{B}+\operatorname{sdj} S S_{C}+\operatorname{sdj} S S_{D}+\operatorname{adj} S S_{A B}+\operatorname{adj} S S_{A C}+ \\
\operatorname{adj} S S_{A D}+\operatorname{adj} S S_{B C}+\operatorname{adj} S S_{B D}+\operatorname{adj} S S_{C D}+\operatorname{adj} S S_{\text {Error }}
\end{array}
$$


Where:

$$
\begin{array}{r}
a d j S S_{A}=b * c * d * \sum_{i=1}^{a}\left(\bar{y}_{i . .}-\bar{y}_{\ldots .}\right)^{2}, \\
a d j S S_{B}=a * c * d * \sum_{j=1}^{b}\left(\bar{y}_{. j . .}-\bar{y}_{\ldots .}\right)^{2}, \\
a d j S S_{C}=a * b * d * \sum_{k=1}^{c}\left(\bar{y}_{. . k .}-\bar{y}_{\ldots .}\right)^{2}, \\
a d j S S_{D}=a * b * c * \sum_{l=1}^{d}\left(\bar{y}_{\ldots l}-\bar{y}_{\ldots .}\right)^{2}, \\
a d j S S_{A B}=c * d * \sum_{i=1}^{a} \sum_{j=1}^{b}\left(\bar{y}_{i j . .}-\bar{y}_{i \ldots}-\bar{y}_{. j . .}-\bar{y}_{\ldots .}\right)^{2}, \\
a d j S S_{A C}=b * d * \sum_{i=1}^{a} \sum_{k=1}^{c}\left(\bar{y}_{i . k .}-\bar{y}_{i \ldots}-\bar{y}_{. . k .}-\bar{y}_{\ldots .}\right)^{2}, \\
a d j S S_{A D}=b * c * \sum_{i=1}^{a} \sum_{l=1}^{d}\left(\bar{y}_{i . . l}-\bar{y}_{i \ldots}-\bar{y}_{\ldots l}-\bar{y}_{\ldots .}\right)^{2}, \\
a d j S S_{C D}=a * b * \sum_{k=1}^{c} \sum_{l=1}^{c}\left(\bar{y}_{. . k l}-\bar{y}_{. . k .}-\bar{y}_{\ldots l}-\bar{y}_{\ldots .}\right)^{2}, \\
a d j S S_{B D}=a * c * \sum_{j=1}^{b} \sum_{l=1}^{d}\left(\bar{y}_{. j . l}-\bar{y}_{. j . .}-\bar{y}_{\ldots l}-\bar{y}_{\ldots .}\right)^{2}, \\
a d j S S_{B C}=a * d * \sum_{j=1} \sum_{k=1}\left(\bar{y}_{. j k .}-\bar{y}_{. j . .}-\bar{y}_{. . k .}-\bar{y}_{\ldots .}\right)^{2},
\end{array}
$$

The adjusted average of squares of every term in an ANOVA table is computed by dividing the corresponding adjusted sum of squares value by its number of DoF. The FValues are computed by dividing the corresponding value of every adjusted average of squares term by the value of the adjusted average of squares of the error term. Finally, the P-Values are obtained using a F-test statistic table with the adequate DoF for the numerator and denominator of every statistical term tested.

\section{APPENDIX B: COLLAPSE MULTIPLIERS}

This appendix contains the results obtained in terms of collapse multipliers for all the simulations performed. 
TABLE 5: Collapse multipliers obtained for every simulation.

\begin{tabular}{|c|c|c|c|c|}
\hline $2: 1$ & $4: 1$ & Running & 0.27 & 0.2700 \\
\hline $1: 1$ & $4: 1$ & Running & 0.27 & 0.2700 \\
\hline $1: 2$ & $4: 1$ & Running & 0.27 & 0.2700 \\
\hline $2: 1$ & $2: 1$ & Running & 0.27 & 0.2700 \\
\hline $1: 1$ & $2: 1$ & Running & 0.27 & 0.2700 \\
\hline $1: 2$ & $2: 1$ & Running & 0.27 & 0.2600 \\
\hline $2: 1$ & $1: 1$ & Running & 0.27 & 0.2386 \\
\hline $1: 1$ & $1: 1$ & Running & 0.27 & 0.2049 \\
\hline $1: 2$ & $1: 1$ & Running & 0.27 & 0.1884 \\
\hline $2: 1$ & $4: 1$ & Stack & 0.27 & 0.2700 \\
\hline $1: 1$ & $4: 1$ & Stack & 0.27 & 0.1750 \\
\hline $1: 2$ & $4: 1$ & Stack & 0.27 & 0.0880 \\
\hline $2: 1$ & $2: 1$ & Stack & 0.27 & 0.1758 \\
\hline $1: 1$ & $2: 1$ & Stack & 0.27 & 0.0889 \\
\hline $1: 2$ & $2: 1$ & Stack & 0.27 & 0.0437 \\
\hline $2: 1$ & $1: 1$ & Stack & 0.27 & 0.0912 \\
\hline $1: 1$ & $1: 1$ & Stack & 0.27 & 0.0443 \\
\hline $1: 2$ & $1: 1$ & Stack & 0.27 & 0.0218 \\
\hline $2: 1$ & $4: 1$ & English & 0.27 & 0.2700 \\
\hline $1: 1$ & $4: 1$ & English & 0.27 & 0.2700 \\
\hline $1: 2$ & $4: 1$ & English & 0.27 & 0.2700 \\
\hline $2: 1$ & $2: 1$ & English & 0.27 & 0.2700 \\
\hline $1: 1$ & $2: 1$ & English & 0.27 & 0.2670 \\
\hline $1: 2$ & $2: 1$ & English & 0.27 & 0.2335 \\
\hline $2: 1$ & $1: 1$ & English & 0.27 & 0.2158 \\
\hline $1: 1$ & $1: 1$ & English & 0.27 & 0.1915 \\
\hline $1: 2$ & $1: 1$ & English & 0.27 & 0.1820 \\
\hline $2: 1$ & $4: 1$ & Flemish & 0.27 & 0.2700 \\
\hline $1: 1$ & $4: 1$ & Flemish & 0.27 & 0.2700 \\
\hline $1: 2$ & $4: 1$ & Flemish & 0.27 & 0.2700 \\
\hline $2: 1$ & $2: 1$ & Flemish & 0.27 & 0.2700 \\
\hline $1: 1$ & $2: 1$ & Flemish & 0.27 & 0.2700 \\
\hline $1: 2$ & $2: 1$ & Flemish & 0.27 & 0.2482 \\
\hline $2: 1$ & $1: 1$ & Flemish & 0.27 & 0.2237 \\
\hline
\end{tabular}


TABLE 5 - Continued from previous page

\begin{tabular}{|c|c|c|c|c|}
\hline Panel ratio & Block ratio & Bond type & Friction ratio & Collapse multiplier \\
\hline $1: 1$ & $1: 1$ & Flemish & 0.27 & 0.2115 \\
\hline $1: 2$ & $1: 1$ & Flemish & 0.27 & 0.2040 \\
\hline $2: 1$ & $4: 1$ & Running & 0.60 & 0.6000 \\
\hline $1: 1$ & $4: 1$ & Running & 0.60 & 0.6000 \\
\hline $1: 2$ & $4: 1$ & Running & 0.60 & 0.4273 \\
\hline $2: 1$ & $2: 1$ & Running & 0.60 & 0.5004 \\
\hline $1: 1$ & $2: 1$ & Running & 0.60 & 0.4352 \\
\hline $1: 2$ & $2: 1$ & Running & 0.60 & 0.3597 \\
\hline $2: 1$ & $1: 1$ & Running & 0.60 & 0.3098 \\
\hline $1: 1$ & $1: 1$ & Running & 0.60 & 0.2873 \\
\hline $1: 2$ & $1: 1$ & Running & 0.60 & 0.2776 \\
\hline $2: 1$ & $4: 1$ & Stack & 0.60 & 0.4191 \\
\hline $1: 1$ & $4: 1$ & Stack & 0.60 & 0.2165 \\
\hline $1: 2$ & $4: 1$ & Stack & 0.60 & 0.1006 \\
\hline $2: 1$ & $2: 1$ & Stack & 0.60 & 0.2245 \\
\hline $1: 1$ & $2: 1$ & Stack & 0.60 & 0.1033 \\
\hline $1: 2$ & $2: 1$ & Stack & 0.60 & 0.0477 \\
\hline $2: 1$ & $1: 1$ & Stack & 0.60 & 0.1086 \\
\hline $1: 1$ & $1: 1$ & Stack & 0.60 & 0.0491 \\
\hline $1: 2$ & $1: 1$ & Stack & 0.60 & 0.0229 \\
\hline $2: 1$ & $4: 1$ & English & 0.60 & 0.6000 \\
\hline $1: 1$ & $4: 1$ & English & 0.60 & 0.5636 \\
\hline $1: 2$ & $4: 1$ & English & 0.60 & 0.4108 \\
\hline $2: 1$ & $2: 1$ & English & 0.60 & 0.4620 \\
\hline $1: 1$ & $2: 1$ & English & 0.60 & 0.4097 \\
\hline $1: 2$ & $2: 1$ & English & 0.60 & 0.3518 \\
\hline $2: 1$ & $1: 1$ & English & 0.60 & 0.2954 \\
\hline $1: 1$ & $1: 1$ & English & 0.60 & 0.2797 \\
\hline $1: 2$ & $1: 1$ & English & 0.60 & 0.2736 \\
\hline $2: 1$ & $4: 1$ & Flemish & 0.60 & 0.6000 \\
\hline $1: 1$ & $4: 1$ & Flemish & 0.60 & 0.5886 \\
\hline $1: 2$ & $4: 1$ & Flemish & 0.60 & 0.4236 \\
\hline $2: 1$ & $2: 1$ & Flemish & 0.60 & 0.4883 \\
\hline $1: 1$ & $2: 1$ & Flemish & 0.60 & 0.4535 \\
\hline $1: 2$ & $2: 1$ & Flemish & 0.60 & 0.3699 \\
\hline
\end{tabular}

Continued on next page 
TABLE 5 - Continued from previous page

\begin{tabular}{|c|c|c|c|c|}
\hline Panel ratio & Block ratio & Bond type & Friction ratio & Collapse multiplier \\
\hline $2: 1$ & $1: 1$ & Flemish & 0.60 & 0.3419 \\
\hline $1: 1$ & $1: 1$ & Flemish & 0.60 & 0.3346 \\
\hline $1: 2$ & $1: 1$ & Flemish & 0.60 & 0.3155 \\
\hline $2: 1$ & $4: 1$ & Running & 1.00 & 1.0000 \\
\hline $1: 1$ & $4: 1$ & Running & 1.00 & 0.8958 \\
\hline $1: 2$ & $4: 1$ & Running & 1.00 & 0.4668 \\
\hline $2: 1$ & $2: 1$ & Running & 1.00 & 1.0000 \\
\hline $1: 1$ & $2: 1$ & Running & 1.00 & 0.6904 \\
\hline $1: 2$ & $2: 1$ & Running & 1.00 & 0.4277 \\
\hline $2: 1$ & $1: 1$ & Running & 1.00 & 0.6039 \\
\hline $1: 1$ & $1: 1$ & Running & 1.00 & 0.4307 \\
\hline $1: 2$ & $1: 1$ & Running & 1.00 & 0.3480 \\
\hline $2: 1$ & $4: 1$ & Stack & 1.00 & 1.0000 \\
\hline $1: 1$ & $4: 1$ & Stack & 1.00 & 0.3996 \\
\hline $1: 2$ & $4: 1$ & Stack & 1.00 & 0.1326 \\
\hline $2: 1$ & $2: 1$ & Stack & 1.00 & 0.5679 \\
\hline $1: 1$ & $2: 1$ & Stack & 1.00 & 0.1591 \\
\hline $1: 2$ & $2: 1$ & Stack & 1.00 & 0.0579 \\
\hline $2: 1$ & $1: 1$ & Stack & 1.00 & 0.2161 \\
\hline $1: 1$ & $1: 1$ & Stack & 1.00 & 0.0660 \\
\hline $1: 2$ & $1: 1$ & Stack & 1.00 & 0.0263 \\
\hline $2: 1$ & $4: 1$ & English & 1.00 & 1.0000 \\
\hline $1: 1$ & $4: 1$ & English & 1.00 & 0.8574 \\
\hline $1: 2$ & $4: 1$ & English & 1.00 & 0.4572 \\
\hline $2: 1$ & $2: 1$ & English & 1.00 & 0.8358 \\
\hline $1: 1$ & $2: 1$ & English & 1.00 & 0.6143 \\
\hline $1: 2$ & $2: 1$ & English & 1.00 & 0.4172 \\
\hline $2: 1$ & $1: 1$ & English & 1.00 & 0.4948 \\
\hline $1: 1$ & $1: 1$ & English & 1.00 & 0.3899 \\
\hline $1: 2$ & $1: 1$ & English & 1.00 & 0.3377 \\
\hline $2: 1$ & $4: 1$ & Flemish & 1.00 & 1.0000 \\
\hline $1: 1$ & $4: 1$ & Flemish & 1.00 & 0.8700 \\
\hline $1: 2$ & $4: 1$ & Flemish & 1.00 & 0.4630 \\
\hline $2: 1$ & $2: 1$ & Flemish & 1.00 & 0.9029 \\
\hline $1: 1$ & $2: 1$ & Flemish & 1.00 & 0.7060 \\
\hline
\end{tabular}

Continued on next page

31 Jiménez Rios, January 4, 2022 
TABLE 5 - Continued from previous page

\begin{tabular}{ccccc}
\hline Panel ratio & Block ratio & Bond type & Friction ratio & Collapse multiplier \\
\hline $1: 2$ & $2: 1$ & Flemish & 1.00 & 0.4329 \\
$2: 1$ & $1: 1$ & Flemish & 1.00 & 0.5906 \\
$1: 1$ & $1: 1$ & Flemish & 1.00 & 0.4853 \\
$1: 2$ & $1: 1$ & Flemish & 1.00 & 0.3861 \\
\hline
\end{tabular}

595

\section{DATA AVAILABILITY STATEMENT}

Some or all data, models, or code generated or used during the study are available in a repository or online in accordance with funder data retention policies (Jiménez Rios et al. 2020b; Jiménez Rios et al. 2020a).

\section{ACKNOWLEDGMENT}

This work is supported by: Italian Ministry of University and Research PRIN 2017, project No. 2017HFPKZY (B88D19001130001); Sapienza Research Grants "Progetti Grandi" 2018 (B81G19000060005). Dr. Reccia fully acknowledges the research project funded by Fondazione di Sardegna (F72F20000320007).

\section{REFERENCES}

Addessi, D., De Bellis, M., and Sacco, E. (2016). "A micromechanical approach for the cosserat modeling of composites." Meccanica, 51(3), 569-592.

Addessi, D., Sacco, E., and Di Re, P. (2018). "Multi-scale analysis of masonry structures." Proceedings of the International Masonry Society Conferences, 307-323, $<$ no. 222279>.

Alfano, G. and Sacco, E. (2006). "Combining interface damage and friction in a cohesive-zone model." International Journal for Numerical Methods in Engineering, 68(5), 542-582.

Angelillo, M., Fortunato, A., Gesualdo, A., Iannuzzo, A., and Zuccaro, G. (2018). "Rigid block models for masonry structures." International Journal of Masonry Research and Innovation, 3(4), 349-368 Cited By :15.

Anthoine, A., Magonette, G., and Magenes, G. (1995). "Shear-compression testing and analysis of brick masonry walls." Proceedings of the 10th European conference on earthquake engineering, Vol. 3, 1657-1662.

Baggio, C. and Trovalusci, P. (1993). "Discrete models for jointed block masonry walls." in A. A. Hamid \& H. G. Harris (eds.), Lancaster (PA), Technomic Publishing Co., Vol. 2, 939-949.

Baggio, C. and Trovalusci, P. (1998). "Limit analysis for no-tension and frictional three-dimensional discrete systems." Mechanics of Structures and Machines, 26(3), 287-304.

Baggio, C. and Trovalusci, P. (2000). "Collapse behaviour of three-dimensional brickblock systems using non-linear programming." Structural Engineering and Mechanics, 10(2), 181-195. 
Baraldi, D., De Carvalho Bello, C. B., and Cecchi, A. (2020). "Refined rigid block model for in-plane loaded masonry." Advances in Civil Engineering, 2020 no. 8844759.

Baraldi, D., Reccia, E., and Cecchi, A. (2018). "In plane loaded masonry walls: DEM and FEM/DEM models. A critical review." Meccanica, 53(7), 1613-1628.

Bustamante, A. O. (2003). "Seismic Assessment of Ancient Masonry Structures." Ph.D. thesis, University of Minho, (11).

Capecchi, D., Ruta, G., and Trovalusci, P. (2011). "Voigt and Poincaré's mechanisticenergetic approaches to linear elasticity and suggestions for multiscale modelling." Archive of Applied Mechanics, 81(11), 1573-1584.

Casapulla, C. and Argiento, L. (2018). "In-plane frictional resistances in dry block masonry walls and rocking-sliding failure modes revisited and experimentally validated." Composites Part B: Engineering, 132, 197-213.

Cascini, L., Gagliardo, R., and Portioli, F. (2020). "LiABlock3D: A software Tool for Collapse Mechanism Analysis of Historic Masonry Structures." International Journal of Architectural Heritage, 14(1), 75-94.

Casolo, S. (2004). "Modelling in-plane micro-structure of masonry walls by rigid elements." International Journal of Solids and Structures, 41(13), 3625-3641.

Casolo, S. (2009). "Macroscale modelling of microstructure damage evolution by a rigid body and spring model." Journal of Mechanics of Materials and Structures, 4(3), 551-570.

Cecchi, A. and Sab, K. (2004). "A comparison between a 3d discrete model and two homogenised plate models for periodic elastic brickwork." Int. J. Solids Struct., 41, 2259-2276.

Clementi, F., Ferrante, A., Giordano, E., Dubois, F., and Lenci, S. (2020). "Damage assessment of ancient masonry churches stroked by the central italy earthquakes of 2016 by the non-smooth contact dynamics method." Bulletin of Earthquake Engineering, 18(2), 455-486.

Coulomb, C. A. (1776). Essai sur une application des règles de maximis \& minimis à quelques problèmes de statique, relatifs à l'architecture. Paris : De l'Imprimerie Royale.

Cundall, P. and Hart, R. (1992). "Numerical modelling of discontinua." Engineering Computations, 9(2), 101-113.

Cundall, P. A. and Strack, O. D. L. (1979). "A discrete numerical model for granular assemblies." Geotechnique, 29(1), 47-65 Cited By :10985.

D’Altri, A., Sarhosis, V., Milani, G., Rots, J., Cattari, S., Lagomarsino, S., Sacco, E., Tralli, A., Castellazzi, G., and de Miranda, S. (2020). "Modeling Strategies for the Computational Analysis of Unreinforced Masonry Structures: Review and Classification." Archives of Computational Methods in Engineering, 27(4), 1153-1185.

Del Piero, G. (1989). "Constitutive equation and compatibility of the external loads for linear elastic masonry-like materials." Meccanica, 24(3), 150-162.

Drougkas, A., Roca, P., and Molins, C. (2015). "Numerical prediction of the behavior, strength and elasticity of masonry in compression." Engineering Structures, 90, 1528. 
Drucker, D. C. (1953). "Coulomb friction, plasticity, and limit loads." Report no., Brown Univ Providence RI DIV of Applied Mathematics.

Drysdale Robert, G. and Hamid Ahmed, A. (2005). "Masonry structures; behaviour and design." Canada Masonry Design Centre.

Dubois, F., Acary, V., and Jean, M. (2018). "The contact dynamics method: A nonsmooth story." Comptes Rendus - Mecanique, 346(3), 247-262 Cited By :28.

Ferris, M. and Tin-Loi, F. (2001). "Limit analysis of frictional block assemblies as a mathematical program with complementarity constraints." International Journal of Mechanical Sciences, 43(1), 209-224.

Gambarotta, L. and Lagomarsino, S. (1997). "Damage models for the seismic response of brick masonry shear walls. part ii: The continuum model and its applications." Earthquake Engineering and Structural Dynamics, 26(4), 441-462.

Gilbert, M., Casapulla, C., and Ahmed, H. (2006). "Limit analysis of masonry block structures with non-associative frictional joints using linear programming." Computers and Structures, 84(13-14), 873-887.

Giuffrè, A. (1990). Letture sulla meccanica delle murature storiche. Kappa.

Greco, F., Leonetti, L., Luciano, R., and Nevone Blasi, P. (2016). "An adaptive multiscale strategy for the damage analysis of masonry modeled as a composite material." Composite Structures, 153, 972-988.

Greco, F., Leonetti, L., Luciano, R., and Trovalusci, P. (2017). "Multiscale failure analysis of periodic masonry structures with traditional and fiber-reinforced mortar joints." Composites Part B: Engineering, 118, 75-95.

Grillanda, N., Chiozzi, A., Milani, G., and Tralli, A. (2019). "Collapse behavior of masonry domes under seismic loads: An adaptive NURBS kinematic limit analysis approach.” Engineering Structures, 200.

Haach, V., Vasconcelos, G., and Lourenço, P. (2011). "Parametrical study of masonry walls subjected to in-plane loading through numerical modeling." Engineering Structures, 33(4), 1377-1389.

Heyman, J. (1966). "The stone skeleton." International Journal of Solids and Structures, 2(2), 249-256,IN1-IN4,257-264,IN5-IN12,265-279.

Heyman, J. (1969). "The safety of masonry arches." International Journal of Mechanical Sciences, 11(4), 363-382,IN3-IN4,383-385.

Huerta Fernández, S. (2004). Arcos, bóvedas y cúpulas. Geometría y equilibrio en el cálculo tradicional de estructuras de fábrica Arcos, bóvedas y cúpulas. Geometría y equilibrio en el cálculo tradicional de estructuras de fábrica. Instituto Juan de Herrera.

Jiménez Rios, A., Pingaro, M., Trovalusci, P., and Reccia, E. (2020a). "Code from the parametric analysis of masonry panels with limit analysis." Zenodo Archive, $<$ https://doi.org/10.5281/zenodo.4321939> (December).

Jiménez Rios, A., Pingaro, M., Trovalusci, P., and Reccia, E. (2020b). "Data from the parametric analysis of masonry panels with limit analysis." Zenodo Archive, $<$ https://doi.org/10.5281/zenodo.4320201> (December).

Kikuchi, K., Yoshimura, K., Tanaka, A., and Yoshida, K. (2003). "Effect of wall aspect ratio on seismic behaviour of reinforced fully grouted concrete masonry walls." 
Proceedings of 9th North American Masonry Conference, 214-225.

Kirsch, U. (1993). Structural optimization: fundamentals and applications. SpringerVerlag Berlin Heidelberg.

Landolfo, R., Gagliardo, R., Cascini, L., Portioli, F., Malena, M., Tomaselli, G., and de Felice, G. (2020). "Rigid block and finite element analysis of settlement-induced failure mechanisms in historic masonry walls." Frattura ed Integrita Strutturale, 14(51), 517-533.

Lemos, J. (2007). "Discrete element modeling of masonry structures." International Journal of Architectural Heritage, 1(2), 190-213.

Leonetti, L., Greco, F., Trovalusci, P., Luciano, R., and Masiani, R. (2018). "A multiscale damage analysis of periodic composites using a couple-stress/Cauchy multidomain model: Application to masonry structures." Composites Part B: Engineering, $141,50-59$.

Lotfi, H. and Shing, P. (1994). "Interface model applied to fracture of masonry structures." Journal of Structural Engineering (United States), 120(1), 63-80.

Lourenço, P. B. (1998). "Experimental and numerical issues in the modelling of the mechanical behaviour of masonry." International Center for Numerical Methods in Engineering.

Lourenço, P. B. (2002). "Computations on historic masonry structures." Progress in Structural Engineering and Materials, 4(3), 301-319.

Lourenço, P. and Rots, J. (1997). "Multisurface interface model for analysis of masonry structures." Journal of Engineering Mechanics, 123(7), 660-668.

Masiani, R. and Trovalusci, P. (1996). "Cosserat and Cauchy materials as continuum models of brick masonry." Meccanica, 31(4), 421-432.

Milani, G. (2011). "Simple lower bound limit analysis homogenization model for in- and out-of-plane loaded masonry walls." Construction and Building Materials, 25(12), 4426-4443.

Milani, G. and Taliercio, A. (2016). "Limit analysis of transversally loaded masonry walls using an innovative macroscopic strength criterion." International Journal of Solids and Structures, 81, 274-293.

Montgomery, D. C. (2019). Design and analysis of experiments. Wiley.

Oliveira, D. and Lourenço, P. (2004). "Implementation and validation of a constitutive model for the cyclic behaviour of interface elements." Computers and Structures, 82(17-19), 1451-1461.

Pau, A. and Trovalusci, P. (2012). "Block masonry as equivalent micropolar continua: The role of relative rotations." Acta Mechanica, 223(7), 1455-1471.

Pepe, M. (2020). "Numerical modeling for masonry: ALMA 2.0, A computational code for the limit analysis of historical masonry structures." Ph.D. thesis, Sapienza University of Rome, (2).

Pepe, M., Pingaro, M., Reccia, E., and Trovalusci, P. (2020a). "Micromodels for the in-plane failure analysis of masonry walls with friction: Limit analysis and demfem/dem approaches." Lecture Notes in Mechanical Engineering, 1883-1895 Conference of 24th Conference of the Italian Association of Theoretical and Applied Mechanics, AIMETA 2019 ; Conference Date: 15 September 2019 Through 19 
September 2019; Conference Code:238859.

Pepe, M., Pingaro, M., and Trovalusci, P. (2021). "Limit analysis approach for the inplane collapse of masonry arches." Proceedings of the Institution of Civil Engineers - Engineering and Computational Mechanics.

Pepe, M., Pingaro, M., Trovalusci, P., Reccia, E., and Leonetti, L. (2020b). "Micromodels for the in-plane failure analysis of masonry walls: Limit analysis, FEM and FEM/DEM approaches." Frattura ed Integrita Strutturale, 14(51), 504-516.

Pepe, M., Sangirardi, M., Reccia, E., Pingaro, M., Trovalusci, P., and de Felice, G. (2020c). "Discrete and Continuous Approaches for the Failure Analysis of Masonry Structures Subjected to Settlements." Frontiers in Built Environment, 6.

Ponte, M., Milosevic, J., and Bento, R. (2019). "Parametrical study of rubble stone masonry panels through numerical modelling of the in-plane behaviour." Bulletin of Earthquake Engineering, 17(3), 1553-1574.

Portioli, F., Casapulla, C., Gilbert, M., and Cascini, L. (2014). "Limit analysis of 3D masonry block structures with non-associative frictional joints using cone programming." Computers and Structures, 143, 108-121.

Portioli, F., Cascini, L., Casapulla, C., and D'Aniello, M. (2013). "Limit analysis of masonry walls by rigid block modelling with cracking units and cohesive joints using linear programming." Engineering Structures, 57, 232-247.

Radenkovic, D. (1961). "Théorèmes limites pour un matériau de Coulomb á dilation non standardisée." Comptes rendus hebdomadaires des séances de l'Académie des Sciences, 252(26), 4103.

Rahman, A. and Ueda, T. (2014). "Experimental investigation and numerical modeling of peak shear stress of brick masonry mortar joint under compression." Journal of Materials in Civil Engineering, 26(9).

Reccia, E., Cazzani, A., and Cecchi, A. (2012). "Fem-dem modeling for out-of-plane loaded masonry panels: A limit analysis approach." Open Civil Engineering Journal, 6(SPEC.ISS.1), 231-238.

Reccia, E., Leonetti, L., Trovalusci, P., and Cecchi, A. (2018). "A multiscale/multidomain model for the failure analysis of masonry walls: A validation with a combined FEM/DEM approach." International Journal for Multiscale Computational Engineering, 16(4), 325-343.

Roca, P., Cervera, M., Gariup, G., and Pela', L. (2010). "Structural analysis of masonry historical constructions. Classical and advanced approaches." Archives of Computational Methods in Engineering, 17(3), 299-325.

Roca, P., Molins, C., and Marí, A. (2005). "Strength capacity of masonry wall structures by the equivalent frame method." Journal of Structural Engineering, 131(10), 1601-1610.

Rossi, M., Calderini, C., Di Napoli, B., Cascini, L., and Portioli, F. (2020). "Structural analysis of masonry vaulted staircases through rigid block limit analysis." Structures, 23, 180-190.

Shrestha, J., Pradhan, S., and Gautam, D. (2020). "In-plane behavior of various brick bonds in masonry walls." Innovative Infrastructure Solutions, 5(2).

Smoljanović, H., Živaljić, N., and Nikolić, . (2013). "A combined finite-discrete ele- 
ment analysis of dry stone masonry structures." Engineering Structures, 52, 89-100. Taguchi, T. and Cuadra, C. (2015). "Influence of bond types on brick masonry strength." The 2015 World Congress on Advances in Structural Engineering and Mechanics (ASEM15).

Tiberti, S., Grillanda, N., Mallardo, V., and Milani, G. (2020). "A Genetic Algorithm adaptive homogeneous approach for evaluating settlement-induced cracks in masonry walls." Engineering Structures, 221.

Trovalusci, P. (2014). "Molecular Approaches for Multifield Continua: origins and current developments." CISM International Centre for Mechanical Sciences, Courses and Lectures, 556, 211-278.

Trovalusci, P. and Masiani, R. (1999). "Material symmetries of micropolar continua equivalent to lattices." International Journal of Solids and Structures, 36(14), 20912108.

Trovalusci, P. and Masiani, R. (2003). "Non-linear micropolar and classical continua for anisotropic discontinous materials." International Journal of Solids and Structures, 40(5), 1281-1297.

Trovalusci, P. and Pau, A. (2014). "Derivation of microstructured continua from lattice systems via principle of virtual works: The case of masonry-like materials as micropolar, second gradient and classical continua." Acta Mechanica, 225(1), 157177.

Vasconcelos, G. and Loureņço, P. (2009). "In-plane experimental behavior of stone masonry walls under cyclic loading." Journal of Structural Engineering, 135(10), 1269-1277. 